Manuscript submitted to Cement and Concrete Research

\title{
Hydration mechanisms of two polymorphs of synthetic ye'elimite
}

A. Cuesta ${ }^{\mathrm{a}}$, G. Álvarez-Pinazo ${ }^{\mathrm{a}}$, S. G. Sanfélix ${ }^{\mathrm{b}}$, I. Peral $^{\mathrm{c}}$, M. A. G. Aranda ${ }^{\mathrm{a}, \mathrm{c}}$, A. G. De la Torre ${ }^{\mathrm{a}, *}$.

a Departamento de Química Inorgánica, Universidad de Málaga, Campus Teatinos S/N. 29071-Málaga, Spain.

${ }^{\mathbf{b}}$ Unidad Técnica de Investigación de Materiales, AIDICO, Avda. Benjamín Franklin, 17 Paterna, Valencia, Spain.

c ALBA-CELLS synchrotron, Carretera BP 1413, Km. 3.3, E-08290 Cerdanyola, Barcelona, Spain.

* Corresponding author. Tel.: +34952131877; fax: +34952132000.

E-mail address: mgd@uma.es (A.G. De la Torre) 


\section{Abstract}

2 Ye'elimite is the main phase in calcium sulfoaluminate cements and also a key phase in sulfobelite

3 cements. However, its hydration mechanism is not well understood. Here we reported new data on

4 the hydration behaviour of ye'elimite using synchrotron and laboratory powder diffraction coupled

5 to the Rietveld methodology. Both internal and external standard methodologies have been used to

6 determine the overall amorphous contents. We have addressed the standard variables: water-to-

7 ye'elimite ratio and additional sulfate sources of different solubility. Moreover, we report a deep

8 study of the role of the polymorphism of pure ye'elimites. The hydration behaviour of orthorhombic

9 stoichiometric and pseudo-cubic solid-solution ye'elimites is discussed. In the absence of additional

10 sulfate sources, stoichiometric-ye'elimite reacts slower than solid-solution-ye'elimite, and AFm-

11 type phases are the main hydrated crystalline phases, as expected. Moreover, solid-solution-

12 ye'elimite produces higher amounts of ettringite than stoichiometric-ye'elimite. However, in the 13 presence of additional sulfates, stoichiometric-ye'elimite reacts faster than solid-solution-ye'elimite.

16 Keywords: Hydration mechanism (A), Rietveld method (B), dissolution and crystallization kinetics 17 (A), calcium sulfoaluminate (D) ye'elimite (D). 


\section{Introduction}

2 Ye'elimite is the most important phase in calcium sulfoaluminate cements (CSA) [1], which are 3 very promising environmentally-friendly materials. These cements address one of the major 4 concerns of the cement industry as they allow decreasing the $\mathrm{CO}_{2}$ footprint of cement production. On average, for every ton of ordinary Portland cement (OPC) produced, 0.97 tons of $\mathrm{CO}_{2}$ are released into the atmosphere, with the cement industry contributing around 6\% of all anthropogenic $\mathrm{CO}_{2}$ emissions translating into approximately $4 \%$ of the planet's global warming[2]. By comparison, CSA cements are produced with significantly lower $\mathrm{CO}_{2}$ emissions relative to OPC, achieved through the use of lower amount of carbonated raw-materials (part of calcite is replaced by gypsum) and a reduced clinkering temperature [1]. The overall $\mathrm{CO}_{2}$ emission reduction can amount up to $40 \%$ [3]. CSA binders may have quite variable compositions, but all of them contain ye'elimite phase, $\mathrm{Ca}_{4} \mathrm{Al}_{6} \mathrm{O}_{12} \mathrm{SO}_{4}$, also called Klein's salt or tetracalcium trialuminate sulfate $\left(\mathrm{C}_{4} \mathrm{~A}_{3} \bar{S}\right.$ in cement nomenclature) as their main phase [4,5]. The term CSA cements are usually reserved for those clinkers containing more than $50 \mathrm{wt} \%$ of ye'elimite and they may also have minor amount of phases as belite, tetracalcium aluminoferrate, anhydrite, gehlenite or mayenite [6]. Cements with large amounts of ye'elimite may have special applications such as high strength developments at early-ages [7]. Ye'elimite is also present, $25 \mathrm{wt} \%$, in sulfobelite cements [8,9].

CSA cements were introduced into the Chinese market as a result of the high-performing and dimensionally-stable cementitious matrices develop by China Building Materials Academy [10]. In Europe, the use of CSA cements is limited by the lack of standards concerning special cements derived from non-Portland clinkers. Nevertheless, the manufacture and marketing of CSA cements has recently been started by several European cement companies [4,11-13].

This work is focus on the reactivity of ye'elimite. Stoichiometric ye'elimite has been reported to be orthorhombic at room temperature $[(14,15]$ and solid solutions of this phase crystallize in a cubic structure [16,17]. There are some studies about the influence of clinkering process on mineral formation of calcium sulfoaluminate based clinkers $[18,19]$. They have proved that minor elements, such as iron, form solid solution with ye'elimite and stabilize the cubic form. The effect of ye'elimite polymorphism on hydration mechanism has been also addressed. However, these systems are complex and there are too many parameters, f.i. type and amount of sulfate source, belite polymorphism, water/solid ratio, etc., affecting the hydration mechanisms. Consequently, a 31 simplification of the problem by the study of pure phases is advisable.

32 During early age hydration of ye'elimite in the presence of a sulfate source like gypsum, bassanite or anhydrite, ettringite (AFt, $\mathrm{C}_{6} \mathrm{~A} \bar{S}_{3} \mathrm{H}_{32}$ ) phase is the main crystalline hydration product, reaction 
1 (1) [20, 21]. On the other hand, ye'elimite is able to react with water to form AFm (monosulfate)

2 according to reaction (2) [20]. In both reactions amorphous aluminium hydroxide is formed.

$3 \mathrm{C}_{4} \mathrm{~A}_{3} \bar{S}+2 \mathrm{C} \bar{S} \mathrm{H}_{\mathrm{x}}+(38-2 \mathrm{x}) \mathrm{H} \rightarrow \mathrm{C}_{6} \mathrm{~A}_{3} \mathrm{H}_{32}+2 \mathrm{AH}_{3}$

$\mathrm{C}_{4} \mathrm{~A}_{3} \bar{S}+18 \mathrm{H} \quad \rightarrow \quad \mathrm{C}_{4} \mathrm{~A} \bar{S} \mathrm{H}_{12}+2 \mathrm{AH}_{3}$

It is known [20,21] that for molar ratios of calcium sulfate to ye'elimite larger than 2, only reaction (1) is taking place. However, there are some contradictory results concerning the reactivity of ye'elimite with water in the absence of another sulfate source. Some authors stated that only reaction (2) takes place [20] while others have published that mixtures of AFt and AFm phases are produced [19, 22].

On the other hand, X-ray powder diffraction (XRPD) is very well suited for in-situ studies of chemical processes involving crystalline materials [23, 24]. During the last years, it has been reported quantitative phase analysis of cements, clinkers and supplementary cementitious materials by combining XRPD and Rietveld methodology [13, 25-27]. This combination results in Rietveld quantitative phase analysis (RQPA). More recently, this procedure has been expanded to hydrated cementitious systems [23, 28] and in some of these studies, the non diffracting fraction was determined [29-31], although a more precise term has been coined: Amorphous and Crystalline notquantified, content [32]. Furthermore, the use of an intense X-ray source, such as synchrotron Xrays, coupled with a fast X-ray detection system permits time-resolved diffraction experiments allowing in-situ measurements during the hydration process of cements [19, 23].

Here, we report a hydration study of two synthetic ye'elimite samples: stoichiometric ye'elimite that presents an orthorhombic unit cell [15] and solid-solution ye'elimite that crystallizes in a pseudo-cubic unit cell. The final goal is to understand the ye'elimite hydration mechanisms as a function of ye'elimite polymorphism, water content and type and content of sulfate source. In order to do so, laboratory and synchrotron XRPD (LXRPD and SXRPD) and Rietveld methodology are employed. Kinetics of hydration have been established and correlated to calorimetric data. This study is a step forward to better understand the eco-cement CSA performances at early ages.

\section{Experimental Section}

\subsection{Sample Preparation.}

Stoichiometric ye'elimite $\left(\mathrm{C}_{4} \mathrm{~A}_{3} \bar{S}\right)$, labelled hereafter $s t-C_{4} A_{3} \bar{S}$, was prepared as previously reported [15]. Solid-solution ye'elimite, labelled $s s-C_{4} A_{3} \bar{S}$ hereafter, was prepared as follows (nominal composition: $\mathrm{Ca}_{3.8} \mathrm{Na}_{0.2} \mathrm{Al}_{5.6} \mathrm{Fe}_{0.2} \mathrm{Si}_{0.2} \mathrm{O}_{12} \mathrm{SO}_{4}$ ). Suitable amounts of $\mathrm{CaCO}_{3}(99.95 \%$, Alfa Aesar), $\mathrm{Al}_{2} \mathrm{O}_{3}$ (99.997\%, Alfa Aesar), $\mathrm{Fe}_{2} \mathrm{O}_{3}$ (99.945\%, Alfa Aesar), $\mathrm{SiO}_{2}$ (99.56\%, ABCR), 
$\mathrm{Na}_{2} \mathrm{CO}_{3}$ (99.999\%, Sigma Aldrich) and $\mathrm{CaSO}_{4} \cdot 2 \mathrm{H}_{2} \mathrm{O}$ (ground natural single-crystal from Málaga) were used to obtain approximately $8 \mathrm{~g}$ of $s s-C_{4} A_{3} \bar{S}$. This composition was chosen following previous studies of active belite CSA [13]. In that work we speculated with the simultaneous presence of $\mathrm{Na}$, Fe and Si within cubic ye'elimite as a consequence of an electron microscopy study. Moreover, it has been previously reported [33] that the cubic symmetry could be restored by substituting larger caged ions for $\mathrm{Ca}^{2+}$ or $\mathrm{SO}_{4}{ }^{2-}$ to expand the framework to a non-collapsed state and by smaller framework cations such as $\mathrm{B}^{3+}, \mathrm{Si}^{4+}$ or $\mathrm{Fe}^{3+}$ for $\mathrm{Al}^{+3}$. Consequently, following our previous results and that information reported by others, we were able to obtain $s s-C_{4} A_{3} \bar{S}$ sample as a pure single phase with the proposed composition. Further details about crystal structure and thermal behaviour of this sample will be published elsewhere.

The mixture was ground for 1 hour in an agate mortar with ethanol. The resulting powder was pelletized (20 mm diameter and $500 \mathrm{MPa}$ ) and heated at $1250^{\circ} \mathrm{C}$ for 4 hours (heating rate of 5 ${ }^{\circ} \mathrm{C} / \mathrm{min}$ ) followed by a rapid cooling. The pellets were ground in an agate mortar. Figure 1 shows the LXRPD raw patterns for both anhydrous samples. St- $C_{4} A_{3} \bar{S}$ sample presents $1.2(2) \mathrm{wt} \%$ of $\mathrm{C}_{3} \mathrm{~A}, 4.4(2) \mathrm{wt} \%$ of CA and 4.0(2) wt\% of $\mathrm{C}_{12} \mathrm{~A}_{7}$ as impurities [15].

St- $C_{4} A_{3} \bar{S}$ and ss- $C_{4} A_{3} \bar{S}$ were mixed with gypsum (g) or anhydrite (a), in some cases, according to the stoichiometry of reactions (1) and (2). Table 1 reports pastes mix proportions, including water/solid (w/s) ratios. The gypsum used for the hydration studies was that marketed by BELITH S.P.R.L. (Belgium). Anhydrite was produced by heating that gypsum at $700^{\circ} \mathrm{C}$ for 1 hour. Blaine fineness for all the samples was ranged between $4400-5000 \mathrm{~cm}^{2} / \mathrm{g}$.

Two experimental set ups were employed: i) in-situ SXRPD and ii) ex-situ LXRPD. For the in-situ SXRPD study all the anhydrous mixtures were mixed with $15 \mathrm{wt} \% \mathrm{SiO}_{2}$ (99.56\%, ABCR) as an internal standard [34] and powder diffraction data were collected to obtain the initial phase assemblage $\left(\mathrm{t}_{0}\right)$. It is important to bear in mind that in the water/solid ratio the amount of internal standard is not taken into account. Pastes were ex-situ prepared and immediately loaded into glass capillaries of $0.5 \mathrm{~mm}$ of diameter with a syringe. The capillaries were sealed with grease to avoid any water loss. Moreover, we were aware that the internal standard could influence the hydration/crystallization processes. We performed an internal study with and without internal standard and check the reproducibility of the Rietveld QPA, observing only minor differences. Consequently, we could trust in the results obtained by this methodology. On the other hand, for the ex-situ LXRPD study, pastes were poured into hermetically closed Teflon ${ }^{\circledR}$ tubes in the form of cylinder until 1 day. Then, the samples were taken out and stored within demineralised water at $20^{\circ} \mathrm{C}$. Pieces were taken out at ages ranging between 2 and 7 days. One fraction of the pastes was milled to fine powder in an agate mortar. In order to stop the hydration process, the procedure was 
1 filtration in a Whatman system (90 mm diameter Whatman filter with a pore size of $2.5 \mu \mathrm{m}$ on a

2 Teflon support) with acetone twice and finally with ether. These samples were stored in a closed

3 desiccator (without vacuum application) to avoid further hydration and/or carbonation.

\subsection{Thermal analysis.}

Differential thermal analysis (DTA) and thermogravimetric (TGA) measurements were performed in a SDT-Q600 analyzer from TA instruments (New Castle, DE) for stopped-hydration pastes. The temperature was varied from RT to $1000^{\circ} \mathrm{C}$ at a heating rate of $10{ }^{\circ} \mathrm{C} / \mathrm{min}$. Measurements were carried out in open platinum crucibles under nitrogen flow. The weighed loss from RT to $600^{\circ} \mathrm{C}$ was computed to be water (chemically bounded water) and that from 600 to $1000^{\circ} \mathrm{C}$ was considered as $\mathrm{CO}_{2}$. Table 2 and Figure S1, S2 and S3 (given as supporting information) report the TGA results.

\subsection{Laboratory X-Ray powder diffraction (LXRPD) and Synchrotron X-Ray powder} diffraction (SXRPD). LXRPD data were recorded on an X'Pert MDP PRO diffractometer (PANalytical) equipped with a Ge (111) primary monochromator, using strictly monochromatic CuK $\alpha_{1}$ radiation ( $\lambda=1.54059 \AA$ ) and an X'Celerator detector. An overall measurement time of $\sim 4 \mathrm{~h}$ per pattern was required for good statistics over the angular range $5.0-70.0^{\circ}(2 \theta)$ with a $0.017^{\circ}$ step size.

SXRPD patters were collected in Debye-Scherrer (transmission) mode using the X-ray powder diffraction station of ALBA synchrotron (Barcelona, Spain) [35]. The wavelength, 0.61975(1) Å, was selected with a double-crystal Si (111) monochromator and determined from Si640d NIST standard ( $\mathrm{a}=5.43123 \AA$ ). The diffractometer is equipped with a MYTHEN detector especially suited for time-resolved experiments. The capillaries were rotated during data collection to improve diffracting particle statistics and the synchrotron beam was focused in the detector to improve the diffraction peak shape. The data acquisition time was 15 min per pattern to attain very good signal-to-noise ratio over the angular range $1-35^{\circ}(2 \theta)$. The temperature inside the experimental hutch was $26(1)^{\circ} \mathrm{C}$.

\subsection{XRPD Data Analysis.}

Raw SXRPD patterns were normalized taking into account the decay of X-ray beam flux with time. SXRPD and LXRPD patterns were analysed by using the Rietveld methodology as implemented in the GSAS software package [36], in order to obtain RQPA. The refined overall parameters were background coefficients, cell parameters, zero-shift error, peak shape parameters, and phase scales. Peak shapes were fitted by using the pseudo-Voigt function [37]. The ACn contents were determined by internal standard methodology [34] from SXRPD data and by external standard method (G-factor) from LXRPD data as detail previously [13, 30] 
1 2.5. Calorimetry. The isothermal calorimetric study was performed in an eight channel Thermal

2 Activity Monitor (TAM) instrument using glass ampoules. Pastes were prepared ex-situ by mixing

$3 \sim 6 \mathrm{~g}$ of each sample with the appropriated water and were immediately introduced in the 4 calorimeter. A stabilization period of 45 minutes was needed to start the measurements. The heat 5 flow was collected up to 7 days at $20^{\circ} \mathrm{C}$.

\section{Results and discussions}

3.1. Hydration of stoichiometric ye'elimite with variable water/solid ratios and without additional sulfate source.

9 Hydration mechanism of $s t-C_{4} A_{3} \bar{S}$ was initially studied without additional sulfate source and two 10 different w/s ratios (0.58 and 1.16), see Table 1 . These pastes have been studied at early ages, up to 1130 hours, by in-situ SXRPD with internal standard methodology. Time-resolved SXRPD was employed to track the dissolution of the anhydrous phases followed by the crystallization of the different hydrated phases (AFt and AFm). Moreover, the pastes were also prepared into cylinders and studied with the external standard methodology, G-factor, at 2 days and 7 days by ex-situ LXRPD.

The w/s ratio of 0.58 corresponds to the stoichiometric amount of water according to reaction (2) with $10 \%$ of excess. The w/s value of 1.16 is the double of the previous value to study the effect of large water excess on hydration mechanisms. Table 3 shows the phase assemblages at different ages for $s t-C_{4} A_{3} \bar{S}_{-} 0.58$ mixture. It is clear that for this w/s ratio the dissolution (and reaction) rate is very slow, since up to 30 hours very small amount of ye'elimite was dissolved and there are no new crystalline hydrates. After 2 days ye'elimite was partially dissolved and the precipitation of small quantities of AFm and AFt were quantified. This observation indicates that both reactions (2) and (1) are taking place. This observation disagrees with the thermodynamic calculation that predicts that only reaction (2) should take place [20]. However, this experimental behaviour has been previously reported [22].

However, to disentangle the extension of both reactions is not an easy task. Interconversion between AFt and AFm may take place depending upon the experimental conditions including the sulfate concentration in the pore water. It has been observed that the crystallization of ettringite reaches a maximum at 2 days of hydration, see Table 3, and then it diminishes. This effect has consequently caused a lack of sulfate ions in the pore solution. For longer hydration times, the formation of AFm

31 is favoured not only from ye’elimite reaction but also likely from AFt dissolution.

32 It is well known that higher amounts of water enhance ye'elimite reactivity [38]. Thus, a paste with w/s of 1.16 was also prepared, st- $C_{4} A_{3} \bar{S} \_1.16$. Figure 2 shows raw SXRPD and LXRPD patterns as 
1 a function of time, with peaks due to a given phase labelled. Table 4 gives RQPA results for st-

$2 C_{4} A_{3} \bar{S} \_1.16$ from SXRPD and LXRPD data. Figure 3a shows the degree of reaction of ye'elimite 3 with water. Comparing Tables 3 and 4 and inspecting Figure 3a it is confirmed that reactivity has been enhanced, achieving over $75 \%$ of degree of reaction at 7 days with w/s 0.58 and 20 hours, with w/s 1.16. Calorimetric data, see Table 1 and Figure S5, show that more heat is released for w/s ratio of 1.16 than for 0.58 , which is in full agreement with a larger reaction degree. In this case, the main hydration product has been AFm, at all hydration times, indicating that higher amounts of water favour reaction (2). This behaviour is in agreement with that previously reported in [20], where only AFm was obtained with a w/s ration of 2.0. However, w/s ratio of 1.16 is not high enough to avoid reaction (1) and a small amount of AFt is also quantified. It is also observed that AFt content is maximum at 2 days, and at later ages partly reacts.

The quantification of AFm-type phases presents two important problems: i) broad diffraction peaks due to both poor crystallinity and highly disorder structures and ii) the lack of structural descriptions for some phases. Thus, the crystal structure reported for $\mathrm{C}_{4} \mathrm{~A} \bar{S} \mathrm{H}_{12}$ [39] has been used to quantify all AFm-type phases by adjusting c-values, as previously reported [19]. Other AFm type phases, such as mono- and hemicarbonate AFm phases [40,41], were checked but they did not fit properly the patterns. The AFm contents reported in Tables 3 and 4 are expressed as the total amount of AFm-type phases. Figure 5 shows Rietveld plots of $s t-C_{4} A_{3} \bar{S}_{-} 1.16$ at 2 days of hydration where all the AFm-types phases have been labelled, as an example of a complex sample. Moreover, we have observed that stopping procedure has affected the mineralogical composition, especially AFm-type phases [42]. In the in-situ synchrotron experiment, the hydration was not stopped and higher crystallinity and no modifications of its basal spacing was observed, see Figure 2 up to $31 \mathrm{~h}$ of hydration. On the other hand, the ex-situ LXRPD data were collected for stopped samples and broader peaks are observed. Three AFm-type phases with modified c-values are needed to fit the pattern, see broad peaks labelled with a star in Figure 2 at 2 days.

Tables 3 and 4 include the ACn values obtained from internal and external standard methodologies. The first column gives $t_{0}$ values obtained from the SXRPD pattern of the anhydrous samples. Free water, FW, in this column is the theoretical value. Remaining values obtained from internal standard method encompass not only ACn but also FW (not chemically bound water) and are expressed as a single value in Tables 3 and 4. This is due to the inability of the internal standard methodology to distinguish between different not-diffracting phases. On the other hand, data obtained with G-factor methodology from LXRPD, 2 days and 7 days, corresponds only to ACn values, since FW was removed by the stopping hydration procedure. The FW contents were determined by the difference between the 'theoretical/mixed' water and the combined water 
1 determined from TGA study (from RT to $600^{\circ} \mathrm{C}$ ), Table 2 and Figures S1, S2 and S3. Consequently,

2 in Tables 3 and 4, ACn and FW values are given for data obtained from LXRPD. It is important to

3 highlight that the results obtained by the internal standard method are in agreement with those

4 obtained at later ages showing the consistence of both methodologies.

\subsection{Hydration of ye'elimite as function of polymorphism and without additional sulfate} source.

In order to understand the role of polymorphism in the hydration mechanism, a solid-solution ye'elimite paste, with a w/s ratio of 1.16 , $\left(s s-C_{4} A_{3} \bar{S} \_1.16\right)$, has also been studied. Table 5 shows

9 RQPA results at the measured ages. Comparing Tables 4 and 5, it can be observed that solidsolution ye'elimite reacts at a faster pace since after 12 hours the degree of reaction of ye'elimite is 75\%, Figure 3a. In addition to a faster kinetics, solid-solution ye'elimite yields much larger relative amounts of AFt. Figures 4a and $4 \mathrm{~b}$ show the evolution of sulfate content with time for st$C_{4} A_{3} \bar{S} \_1.16$ and $s s-C_{4} A_{3} \bar{S} \_1.16$ pastes. The amount of residual sulfate content was calculated using the quantitative data reported in Tables 4 and 5 for $C_{4} A_{3} \bar{S}$, given as solid symbols. In addition, the crystallized sulfate content was calculated from the quantified ettringite in Figure 4a (crossed symbols) and global sulfate content from the amounts of ettringite jointly with AFm-phases in Figure 4b. The dotted and dashed lines in Figures 4a and 4b represents the maximum sulfate group content which can crystallize in each sample. As mentioned before, AFt crystallization in ss$C_{4} A_{3} \bar{S}$ is higher than in the stoichiometric sample. Moreover, $17 \%$ and $\sim 10 \%$ of hydrated sulfate groups for $s t-C_{4} A_{3} \bar{S}$ and $s s-C_{4} A_{3} \bar{S}$, respectively were mainly incorporated into ACn phase(s) and/or in pore solution. Consistently with the former two studies, after two days the amount of AFt starts to decrease. Calorimetric data, see Table 1 and Figure S5 (given as supporting information), show that more heat is released by the solid-solution sample, due to a larger reaction degree of solidsolution-ye'elimite and also to a larger relative amount of ettringite at seven days. The higher dissolution rate of $s s-C_{4} A_{3} \bar{S}$ may be related by the release of $\mathrm{Na}^{+}$to the pore solution, provoking a similar effect (although less pronounced) than $\mathrm{KOH}[20]$. 
1 This third study is mainly focused on the soluble sulfate (gypsum and anhydrite) effect in the

2 hydration of ye'elimite. Both ye'elimites, stoichiometric and solid-solution, have been studied with both type of sulfates, see Table $1 . s t-C_{4} A_{3} \bar{S}$ was studied with two w/s ratios, 0.71 and 1.42 . The w/s ratio of 0.71 corresponds to the theoretical water, according to reaction (1) plus an excess of 10 wt $\%$. The w/s ratio of 1.42 is the double of the latter to study the influence of a large w/s ratio. Tables S1 and S2 show the RQPA obtained by SXRPD of these two mixtures. Firstly, AFm is not observed and so only reaction (1) takes place, as expected. Secondly, the phase assemblage is not modified with the increase of the w/s ratio but the reaction is accelerated, see Figure 3b. Finally, from the in-situ SXRPD study it was observed that over 12 hours of hydration the dissolution of reactants was complete for most of the samples, see Figure 3b. Consequently, these pastes have only been studied by in-situ SXRPD.

To study the role of ye'elimite polymorphism in the hydration reactions, $s t-C_{4} A_{3} \bar{S} \_g \_1.42$ and ss$C_{4} A_{3} \bar{S} \_$g_1.42 mixtures were prepared. RQPA obtained from SXRPD are given in Tables S2 and S3. Moreover, the full phase content evolution is displayed in Figure 6, where calorimetric data are also included. The calorimetric curve shows a broad and intense signal (between 5 to 12 hours of hydration) associated to dissolution and precipitation processes [20]. The times for the maximum heat release agree well with the progress of the reactions observed by SXRPD. For both pastes, the reaction has almost finished after 14 hours of hydration, with a degree of reaction for ye'elimite being $\sim 100 \%$ and $\sim 85 \%$, for stoichiometric and solid-solution ye'elimite, respectively, see Figure 3b. Moreover, the overall reactivity of these two samples has also followed reaction (1). AFt is the only crystalline hydrated product, consequently there should be an amorphous phase with stoichiometry close to $\mathrm{AH}_{3}$. It is important to note that the hydration of $s t-C_{4} A_{3} \bar{S}$ with a source of sulfate is highly accelerated compared to that of the sample without gypsum.

The time evolution of $\mathrm{ACn}$ and FW contents in $s t-C_{4} A_{3} \bar{S} \_$g_1.42 and ss- $C_{4} A_{3} \bar{S} \_$g_1.42 is reported in Figure 6 and Tables S2 and S3. It can be observed that for both pastes, these values slightly diminished with time. It is worth noting that the opposite behaviour is observed for samples without gypsum. This is mainly due to the larger amounts of ettringite and the absence of AFm-type phases.

28 The main difference found between the hydration of $s t-C_{4} A_{3} \bar{S} \_$g_ 1.42 and that of $s s-C_{4} A_{3} \bar{S} \_$g_1.42 is related to the reaction rate. The presence of gypsum has largely accelerated the hydration kinetic of st- $C_{4} A_{3} \bar{S}$. Figure $3 \mathrm{~b}$ displays the degree of reaction of ye'elimite in the presence of gypsum. It can be observed that stoichiometric sample attained more than 50\% of degree of reaction after 2.5 hours, meanwhile, solid-solution ye'elimite degree of reaction is almost $0 \%$, at that time. This effect 33 has been corroborated by calorimetric measurements since most of the heat evolved by stoichiometric sample is centred around 6 hours while that of $s s-C_{4} A_{3} \bar{S}$ is placed close to 12 hours, 
see Figure S4. On the other hand, the presence of gypsum has accelerated little the hydration of solid-solution ye'elimite. After $\sim 12 \mathrm{~h}$, the degree of reaction reached $\sim 75 \%$, in the absence and presence of gypsum, Figure 3a and 3b, respectively.

A less soluble sulfate source [20], anhydrite, was also used to study its influence on the hydration mechanism of ye'elimite. Table 1 gives the w/s ratio used, following the same criterion as in previous pastes. The anhydrite study has been performed at early ages for the sake of comparison with the gypsum study. Figure 7 shows raw SXRPD patterns as a function of time for st$C_{4} A_{3} \bar{S}_{-}$a_1.62 paste and Table 6 reports the RQPA for this mixture. The main hydration product is, as in the presence of gypsum, ettringite. This is in agreement with reaction (1), although in this case some (minor) amounts of AFm also crystallized during early hydration. The anhydrite is dissolved at a very low pace, disappearing after 7 hours. Consequently, the pore solution was undersaturated in calcium and sulfate with respect to gypsum or anhydrite [20]. As a consequence, AFm partly precipitates or forms at early stage, first few hours. Once anhydrite starts to dissolve, close to the third hour, AFt appears and AFm disappears, see Table 6. AFm content reaches a maximum content at 3 hours under the given experimental conditions.

On the other hand, solid-solution ye'elimite with anhydrite and a w/s ratio of 1.62 has a slower kinetic of hydration. Table 7 shows the phase assemblage as a function of time up to 9 hours. The main difference between stoichiometric and solid-solution ye'elimite is the hydration pace, since ss$C_{4} A_{3} \bar{S}$ reacts slowly and at 9 hours the degree of reaction is as low as $13.5 \%$, see Figure $3 b$ and Table 7. AFm is not observed at any time likely as a consequence of the slow dissolution pace of solid-solution ye'elimite in these conditions. Figure $8 \mathrm{a}$ and $8 \mathrm{~b}$ shows Rietveld plots of st$C_{4} A_{3} \bar{S} \_$a_1.62 and $s s-C_{4} A_{3} \bar{S} \_$a_11.62, respectively, at 3 hours of hydration. This Figure illustrates the presence of both AFt and AFm for $s t-C_{4} A_{3} \bar{S}$ sample, see Figure 8a, and the total absence of hydration products for $s s-C_{4} A_{3} \bar{S}$ one. Calorimetric data have confirmed these differences. For st$C_{4} A_{3} \bar{S}_{\_}$a $\_1.62$, the heat released is much faster than for $s s-C_{4} A_{3} \bar{S} \_$a $\_1.62$, see Figure S4. This observation fully agrees with the diffraction study described just above.

\section{Conclusions}

First of all, it is worth highlighting the successful synthetic procedure of a single phase of doped ye'elimite by the addition of $\mathrm{Na}, \mathrm{Si}$ and Fe in the structure. Moreover, this work reports new data on the mechanisms for early age hydration of ye'elimite. Here we demonstrate that hydration kinetics not only depends on the w/s ratio and the solubility of the additional sulfate source, but also on the polymorphism of ye'elimite. 
1 In the absence of additional sulfate sources, some findings should be highlighted: i) stoichiometric

2 ye'elimite reacts slower than solid-solution ye'elimite; ii) the formation of AFm-type phases from

3 stoichiometric ye'elimite is strongly accelerated by high w/s ratios; iii) in the investigated

4 experimental conditions, w/s ratios of 0.58 and 1.16, a mixture of AFm and AFt has been always

5 found although AFm was the crystalline hydrate phase in major content; and iv) solid-solution ye'elimite produces higher amounts of ettringite than stoichiometric ye'elimite in similar hydrating conditions.

8 In the presence of gypsum or anhydrite as additional sulfate sources, the key findings are: i) stoichiometric ye'elimite reacts faster than solid-solution ye'elimite, and this difference is exacerbated for anhydrite; ii) the formation of AFm-type phases at late ages is avoided by the addition of gypsum and anhydrite; iii) for anhydrite addition, AFm is measured at very early ages (first few hours); iv) the hydration of stoichiometric ye'elimite in the presence of gypsum is accelerated when compared to the corresponding conditions without gypsum; v) the presence of gypsum has little effect in the kinetics of hydration of solid-solution ye'elimite when compared to the hydration if the absence of gypsum; finally and chiefly vi) the hydration of ye'elimite in presence of anhydrite is very much slowed.

\section{Acknowledgements}

This work has been supported by Junta de Andalucía through P11-FQM-7517 research grant and by Spanish MINECO through MAT2010-16213 research grant, which is co-funded by FEDER. ALBA synchrotron is thanked for providing synchrotron beamtime at BL04-MSPD beamline.

\section{References}

[1] F.P. Glasser, L. Zhang, High-performance cement matrices based on calcium sulphoaluminatebelite compositions, Cem. Concr. Res. 31 (2001) 1881-1886.

[2] R.J. Flatt, N. Roussel, C.R. Cheeseman, Concrete: An eco material that needs to be improved, J. Eur. Ceram. Soc. 32 (2012) 2787-2798.

[3] M.A.G.Aranda, A.G. De la Torre, Calcium sulfoaluminate cements and concretes, in Ecoefficient concrete; Ed. F. Pacheco-Torgal, Ed. S.Jalali, Ed. J. Labrincha, Woodhead Publishing: 29 Cambridge, 2013, pp. 488-522.

30 [4] E. Gartner, Industrially interesting approaches to "'low- $\mathrm{CO}_{2}$ "' cements, Cem. Concr. Res. 34 31 (2004), 1489-1498.

32 [5] I. Odler, Special Inorganic Cements, Taylor and Francis, London, 2000.

33 [6] S. Sahu, J. Majling, Phase compatibility in the system $\mathrm{CaO}-\mathrm{SiO}_{2}-\mathrm{Al}_{2} \mathrm{O}_{3}-\mathrm{Fe}_{2} \mathrm{O}_{3}-\mathrm{SO}_{3}$ referred to sulphoaluminate belite cement clinker, Cem. Concr. Res. 23 (1993) 1331-1339.

35 [7] K. Quillin, Performance of belite-sulfoaluminate cements, Cem. Concr. Res. 31 (2001) 1341361349. 
[8] G. Álvarez-Pinazo, I. Santacruz, L. León-Reina, M.A.G. Aranda, A.G. De la Torre, Hydration Reactions and Mechanical Strength Developments of Iron-Rich Sulfobelite Eco-cements, Ind. Eng. Chem. Res. 52 (2013), 16606-16614.

4 [9] V. Morin, G. Walenta, E. Gartner, P. Termkhajornkit, I. Baco, J.M. Casabonne, Hydration of a Congress on the Chemistry of Cement, Madrid, Spain, 2011.

[10] L. Zhang, M. Su, Y. Wang, Development of the use of sulpho-and ferroaluminate cements in China, Adv. Cem. Res. 11 (1999)15-22.

[11] G.S. Li, G. Walenta, E.M. Gartner, Formation and hydration of low- $\mathrm{CO}_{2}$ cements based on belite, calcium sulfoaluminate and calcium aluminoferrite, Proceedings of the 12th ICCC, Montreal, Canada (2007).

[12] M.C.G. Juenger, F. Winnefeld, J.L. Provis, J.H. Ideker, Advances in alternative cementitious binders, Cem. Concr. Res. 41 (2011) 1232-1243.

[13] G. Álvarez-Pinazo, A. Cuesta, M. García-Maté, I. Santacruz, E.R. Losilla, A.G. De la Torre, L. León-Reina, M.A.G. Aranda, Rietveld quantitative phase analysis of Yeelimite-containing cements, Cem. Concr. Res. 42 (2012) 960-971.

[14] N.J. Calos, C.H.L. Kennard, A.K. Whittaker, R.L. Davis, Structure of calcium aluminate sulfate $\mathrm{Ca}_{4} \mathrm{Al}_{6} \mathrm{O}_{16} \mathrm{~S}$, J. Solid State Chem. 119 (1995) 1-7.

[15] A. Cuesta, A.G. De la Torre, E.R. Losilla, V.K. Peterson, P. Rejmak, A. Ayuela, C. Frontera, M.A.G. Aranda, Structure, atomistic simulations, and phase transition of stoichiometric yeelimite, Chem. Mater. 25 (2013) 1680-1687.

[16] O. Andac and F.P. Glasser, Polymorphism of calcium sulphoaluminate $\left(\mathrm{Ca}_{4} \mathrm{Al}_{6} \mathrm{O}_{16} \cdot \mathrm{SO}_{3}\right)$ and its solid solutions, Adv. Cem. Res. 6 (1994) 57-60.

[17] M. Idrissi, A. Diouri, D. Damidot, J.M. Greneche, M. Alami Talbi, M. Taibi, Charactersation of iron inclusion during the formation of calcium sulfoaluminate phase. Cement and Concrete research 40 (2010), 1314-1319.

[18] F. Bullerjahn, D. Schmitt, M. Ben Haha, Effect of raw mix design and of clinkering process on the formation and mineralogical composition of (ternesite) belite calcium sulphoaluminate ferrite clinker, Cem. Concr. Res. 59 (2014) 87-95.

[19] G. Álvarez-Pinazo, A. Cuesta, M. García-Maté, I. Santacruz, E. R. Losilla, L.M. Ordóñez, S. G. Sanfélix, F. Fouth, M.A.G. Aranda, A. G. De la Torre, In-situ early-age hydration study of sulfobelite cements by synchrotron powder diffraction, Cem. Concr. Res. 56 (2014) 12-19.

[20] F. Winnefeld, S. Barlag, Calorimetric and thermogravimetric study on the influence of calcium sulfate on the hydration of ye'elimite, J. Therm. Anal. Calorim. 101 (2010) 949-957.

[21] C.W. Hargis, A.P. Kirchheim, P.J.M. Monteiro, E.M. Gartner, Early age hydration of calcium suloaluminate (synthetic ye'elimite, $\mathrm{C}_{4} \mathrm{~A}_{3} \mathrm{~S}$ ) in the presence of gypsum and varying amounts of calcium hydroxide, Cem. Concr. Res. 48 (2013) 105-115.

[22] S. Berger, C. Cau-Dit-Coumes, P. Le Bescop, D. Daminot, Influence of a thermal cycle at early age on the hydration of calcium sulphoaluminate cements with variable gypsum contents, Cem. Concr. Res. 41 (2011) 149-160.

[23] M. Merlini, G. Artioli, C. Meneghini, T. Cerulli, A. Bravo, F. Cella, The early hydration and the set of Portland cements: In situ X-ray powder diffraction studies, Powder Diffr. 22 (2007) 201208. 
[24] R. Snellings, G. Mertens, R. Adriaens, J. Elsen, In situ synchrotron X-ray powder diffraction study of the early age hydration of cements blended with zeolite and quartzite fines and waterreducing agent, J. Appl. Clay Sci. 72 (2013) 124-131.

[25] A.G. De la Torre, A. Cabeza, A. Calvente, S. Bruque, M.A.G. Aranda, Full phase analysis of Portland clinker by penetrating synchrotron powder diffraction, Anal. Chem. 73 (2001) 151-156.

[26] A.G. De la Torre, M.A.G. Aranda, Accuracy in Rietveld quantitative phase analysis of Portland cements, J. Appl. Cryst. 36 (2003) 1169-1176.

[27] L. León-Reina, A.G. De la Torre, J.M. Porras-Vázquez, M. Cruz, L.M. Ordonez, X. Alcobe, F. Gispert-Guirado, A. Larrañaga-Varga, M. Paul, T. Fuellmann, R. Schmidt, M.A.G. Aranda, Round robin on Rietveld quantitative phase analysis of Portland cements, J. Appl. Cryst. 42 (2009) 906916.

[28] K.L. Scrivener, T. Füllmann, E. Gallucci, G. Walenta, E. Bermejo, Quantitative study of Portland cement hydration by X-ray diffraction/Rietveld analysis and independent methods, Cem. Concr. Res. 34 (2004) 1541-1547.

[29] S.R. Klaus, J. Neubauer, F. Goetz-Neunhoeffer, Hydration kinetics of $\mathrm{CA}_{2}$ and CAInvestigations performed on a synthetic calcium aluminate cement, Cem. Concr. Res. 43 (2013) 6269.

[30] D. Jansen, F. Goetz-Neunhoeffer, C. Stabler, J. Neubauer, A remastered external standard method applied to the quantification of early OPC hydration, Cem. Concr. Res. 41 (2011) 602-608.

[31] S.M. Clark, P. Barnes, A comparison of laboratory, synchrotron and neutron diffraction for the real time study of cement hydration, Cem. Concr. Res. 25 (1995) 639-646.

[32] M.A.G. Aranda, A.G. De la Torre, L. León-Reina, Rietveld Quantitative Phase Analysis of OPC Clinkers, Cements and Hydration Products, Rev. Mineral. Geochem. 74 (2012) 169-209.

[33] C.W. Hargis, J. Moon, B. Lothenbach, F. Winnefeld, H-R. Wenk, P. J.M. Monteiro, Calcium Sulfoaluminate Sodalite $\left(\mathrm{Ca}_{4} \mathrm{Al}_{6} \mathrm{O}_{12} \mathrm{SO}_{4}\right)$ Crystal Structure Evaluation and Bulk Modulus Determination, J. Am. Ceram. Soc. 97 (2014) 892-898.

[34] A.G. De la Torre, S. Bruque, M.A.G. Aranda, Rietveld quantitative amorphous content analysis, J. Appl. Crystallogr. 34 (2001) 196-202.

[35] F. Fauth, I. Peral, C. Popescu, M. Knapp, The new Material Science Powder Diffraction

[36] A.C. Larson, R.B. Von Dreele, General Structure Analysis System (GSAS), Los Alamos National Laboratory Report LAUR (2000) pp 86-748.

[37] P. Thompson, D.E. Cox, J.B. Hasting, Rietveld refinement of Debye-Scherrer synchrotron Xray data from $\mathrm{Al}_{2} \mathrm{O}_{3}$, J. Appl. Cryst. 20 (1987) 79-83.

[38] M. Doval, M. Palou, V. Kovar, Heat evolution and mechanism of hydration in $\mathrm{CaO}-\mathrm{Al}_{2} \mathrm{O}_{3}-$ $\mathrm{SO}_{3}$ system, Ceram. Silik. 49 (2005) 104-108.

[39] R. Allmann, Refinement of the hybrid layer structure $\left[\mathrm{Ca}_{2} \mathrm{Al}(\mathrm{OH})_{6}\right]^{+} \cdot\left[1 / 2 \mathrm{SO}_{4} \cdot 3 \mathrm{H}_{2} \mathrm{O}\right]^{-}$, Neues. Jahrb. Mineral. Monatsh. (1977) 136-144.

[40] M. François, G. Renaudin, O. Evrad, A cementitious compound with composition $3 \mathrm{CaO} \cdot \mathrm{Al}_{2} \mathrm{O}_{3} \cdot \mathrm{CaCO}_{3} \cdot 11 \mathrm{H}_{2} \mathrm{O}$, Acta Cryst. C 54 (1998) 1214-1217.

[41] T. Runcevski, R.E. Dinnebier, O.V. Magdysyuk, H. Pöllmann, Crystal structures of calcium hemicarbo aluminate and carbonated calcium hemicarboaluminate from synchrotron powder diffraction data, Acta Cryst. B 68 (2012) 493-500. 
1 [42] L. Zhang, F.P. Glasser, Critical examination of drying damage to cement pastes, Adv. Cem.

2 Res. $12(2000) 79-88$.

\section{Figure Captions}

Figure 1. Selected range of the LXRPD raw patterns for st $-C_{4} A_{3} \bar{S}$ and $s s-C_{4} A_{3} \bar{S}$. Stars stand for main peaks of minor impurities. Inset detail the low-angle range.

Figure 2. Selected range of the SXRPD and LXRPD raw patterns for $s t-C_{4} A_{3} \bar{S} \_1.16$ recorded at different hydration ages. The main peaks due to a given phase are labelled; AFt: circle, AFm: star, $C_{4} A_{3} \bar{S}$ : square, Qz: triangle.

Figure 3. Degree of dissolution/reaction [ $\alpha$ ] of ye'elimite as a function of time for (a) $s t-C_{4} A_{3} \bar{S}$ and $s s-C_{4} A_{3} \bar{S}$ pastes without additional sulfate source; and (b) $s t-C_{4} A_{3} \bar{S}$ and $s s-C_{4} A_{3} \bar{S}$ pastes with gypsum or anhydrite.

Figure 4. Evolution of sulfate groups in $s t-C_{4} A_{3} \bar{S}_{-} 1.16$ (square) and $s s-C_{4} A_{3} \bar{S}_{-} 1.16$ (circle) for (a) residual (solid symbols) and crystallized only as ettringite (crossed symbols) and (b) residual (solid symbols) and totally crystallized as AFt and AFm-phases (open symbols). Dashed and dotted lines represent the maximum values of sulfate groups that could crystallize.

Figure 5. LXRPD Rietveld plot for $s t-C_{4} A_{3} \bar{S}_{-} 1.16$ at 2 days of hydration, with the main peaks due to a given phase labelled; AFt: circle, AFm: star, $C_{4} A_{3} \bar{S}$ : square.

20 Figure 6. Full quantitative phase analysis results for a) $s t-C_{4} A_{3} \bar{S} \_$_g_1.42 and b) $s s-C_{4} A_{3} \bar{S} \_$g_1.42. Calorimetric heat flow curves (dashed line) are also displayed.

Figure 7. Selected range of the SXRPD raw patterns for $s t-C_{4} A_{3} \bar{S} \_$a_ 1.62 recorded at different hours of hydration, with the main peaks due to a given phase labelled; AFt: circle, AFm: star, $C_{4} A_{3} \bar{S}$ : square, Qz: triangle; $\bar{C} \bar{S}$ : rhombus.

Figure 8. SXRPD Rietveld plots for a) $s t-C_{4} A_{3} \bar{S} \_$a $\_1.62$ at 3 hours of hydration, with the main peaks due to a given phase labelled. Inset: Enlargement of the low angle region. b) ss$C_{4} A_{3} \bar{S} \_$a_1.62, at 3 hours of hydration, with the main peaks due to a given phase labelled; AFt: circle, AFm: star, $C_{4} A_{3} \bar{S}$ : square, Qz: triangle; $\mathrm{C} \overline{\mathrm{S}}$ : rhombus 
Table 1. Paste mix proportions in weight percentages (wt\%). The total heat evolved at 7 days of hydration is also given.

\begin{tabular}{|c|c|c|c|c|c|}
\hline Mixture & $\begin{array}{c}\text { st- } C_{4} A_{3} \bar{S} \\
\text { wt } \%\end{array}$ & $\begin{array}{c}S S-C_{4} A_{3} \bar{S} \\
\text { wt } \% \\
\end{array}$ & $\begin{array}{c}\text { gypsum/anhydrite } \\
\text { wt \% } \\
\end{array}$ & water/solid & $\begin{array}{c}\text { Total heat } \\
(\mathrm{J} / \mathrm{g})\end{array}$ \\
\hline st- $C_{4} A_{3} \bar{S} \_0.58$ & 100 & - & - & 0.58 & 391 \\
\hline st- $C_{4} A_{3} \bar{S} \_1.16$ & 100 & - & - & 1.16 & 555 \\
\hline$s s-C_{4} A_{3} \bar{S} \_1.16$ & - & 100 & - & 1.16 & 577 \\
\hline st- $C_{4} A_{3} \bar{S} \_$g_0.71 & 64.1 & - & $35.9 /-$ & 0.71 & - \\
\hline st- $C_{4} A_{3} \bar{S} \_$g_1.42 & 64.1 & - & $35.9 /-$ & 1.42 & 518 \\
\hline$s s-C_{4} A_{3} \bar{S} \_g \_1.42$ & - & 64.1 & 35.9/- & 1.42 & 488 \\
\hline st- $C_{4} A_{3} \bar{S}$ _a_1.62 & 69.0 & - & $-/ 31.0$ & 1.62 & 566 \\
\hline$s s-C_{4} A_{3} \bar{S} \_\mathrm{a} \_1.62$ & - & 69.0 & $-/ 31.0$ & 1.62 & 544 \\
\hline
\end{tabular}

Table 2. Summary of the weight losses from the TGA study for pastes without additional sulfate source.

\begin{tabular}{|c|c|c|c|c|}
\hline mixture & $\begin{array}{c}\text { Hydration } \\
\text { time / d }\end{array}$ & $\begin{array}{c}\text { Theoretical } \\
\text { weight loss }{ }^{\#} \text { / \% }\end{array}$ & $\begin{array}{c}\text { Weight loss } \\
\text { RT-600 }^{\circ} \mathrm{C} / \% \\
\end{array}$ & $\begin{array}{c}\text { Weight loss } \\
600-1000^{\circ} \mathrm{C} / \%\end{array}$ \\
\hline st- $C_{4} A_{3} \bar{S} \_0.58$ & $\begin{array}{l}2 d \\
7 d\end{array}$ & $\begin{array}{l}36.7 \\
36.7\end{array}$ & $\begin{array}{l}25.5 \\
32.1\end{array}$ & $\begin{array}{l}0.9 \\
1.3\end{array}$ \\
\hline st- $C_{4} A_{3} \bar{S} \_1.16$ & $\begin{array}{l}2 d \\
7 d\end{array}$ & $\begin{array}{l}53.7 \\
53.7\end{array}$ & $\begin{array}{l}36.7 \\
35.8\end{array}$ & $\begin{array}{l}1.5 \\
1.8\end{array}$ \\
\hline$s s-C_{4} A_{3} \bar{S} \_1.16$ & $\begin{array}{l}2 d \\
7 d\end{array}$ & $\begin{array}{l}53.7 \\
53.7\end{array}$ & $\begin{array}{l}38.8 \\
39.9\end{array}$ & $\begin{array}{l}1.8 \\
1.8\end{array}$ \\
\hline
\end{tabular}

\# Theoretical weight loss: total initial free water.

Table 3. Quantitative phase analysis results (wt\%) for st $C_{4} A_{3} \bar{S} \_0.58$ paste, as a function of hydration time obtained by SXRPD and LXRPD. $\mathrm{R}_{\mathrm{WP}}(\%)$ and $\chi^{2}$ Rietveld agreement factors are also given.

\begin{tabular}{c|cccccc}
\hline & \multicolumn{3}{|c|}{ SXRPD } & \multicolumn{3}{c}{ LXRPD } \\
\hline & $\mathbf{t}_{\mathbf{0}}$ & $\mathbf{8 h}$ & $\mathbf{2 4 h}$ & $\mathbf{3 0 h}$ & $\mathbf{2 d}$ & $\mathbf{7 d}$ \\
\hline $\mathbf{s t}-\boldsymbol{C}_{\mathbf{4}} \boldsymbol{A}_{\mathbf{3}} \overline{\boldsymbol{S}}$ & $61.1(1)$ & $54.1(1)$ & $51.6(1)$ & $46.4(1)$ & $34.3(1)$ & $10.6(2)$ \\
$\mathbf{A F t}$ & - & - & $0.3(1)$ & $0.5(1)$ & $6.3(3)$ & $4.7(1)$ \\
$\mathbf{A F m}$ & - & - & $0.6(1)$ & $3.2(1)$ & $7.1(3)$ & $20.2(4)$ \\
$\mathbf{A C n}$ & $2.2(1)$ & $45.9(1)$ & $47.6(1)$ & $49.9(1)$ & $41.0(4)$ & $59.9(5)$ \\
$+\mathbf{F W}$ & $+36.7^{*}=38.9$ & & & & $+11.3=52.3$ & $+4.9=64.5$ \\
$\mathrm{R}_{\mathrm{WP}}(\%)$ & 6.2 & 5.5 & 5.2 & 5.6 & 8.1 & 10.3 \\
$\chi^{2}$ & 29.7 & 30.7 & 28.2 & 25.3 & 4.6 & 7.0 \\
\hline
\end{tabular}

*Theoretical free water content 
Table 4. Quantitative phase analysis results (wt\%) for st- $C_{4} A_{3} \bar{S}_{-} 1.16$ paste, as a function of hydration time obtained by SXRPD and LXRPD. $\mathrm{R}_{\mathrm{WP}}(\%)$ and $\chi^{2}$ Rietveld agreement factors are also given.

\begin{tabular}{c|ccccccc}
\hline & \multicolumn{5}{c}{ SXRPD } & \multicolumn{2}{c}{ LXRPD } \\
\hline & $\mathbf{t}_{\mathbf{0}}$ & $\mathbf{1 2 h}$ & $\mathbf{1 8 h}$ & $\mathbf{2 4 h}$ & $\mathbf{3 1 h}$ & $\mathbf{2 d}$ & $\mathbf{7 d}$ \\
\hline $\mathbf{s t}-\boldsymbol{C}_{4} \boldsymbol{A}_{3} \overline{\boldsymbol{S}}$ & $44.9(1)$ & $43.0(1)$ & $29.4(1)$ & $10.3(3)$ & $9.2(3)$ & $4.6(2)$ & $2.9(2)$ \\
$\mathbf{A F t}$ & - & - & $2.3(1)$ & $1.1(2)$ & $1.0(2)$ & $9.2(3)$ & $6.8(3)$ \\
$\mathbf{A F m}$ & - & - & $7.1(1)$ & $22.0(2)$ & $22.2(2)$ & $25.1(4)$ & $25.8(5)$ \\
$\mathbf{A C n}$ & $1.4(1)$ & $57.0(1)$ & $61.2(1)$ & $66.5(2)$ & $67.6(2)$ & $44.1(5)$ & $46.5(6)$ \\
$+\mathbf{F W}$ & $+53.7^{*}=55.1$ & & & & & $+17=61.1$ & $+17.9=64.4$ \\
$\mathrm{R}_{\mathrm{WP}}(\%)$ & 6.2 & 4.9 & 4.7 & 11.4 & 12.8 & 10.0 & 10.5 \\
$\chi^{2}$ & 29.7 & 20.9 & 20.3 & 137.8 & 199.1 & 7.1 & 7.7 \\
\hline
\end{tabular}

*Theoretical free water content 
Table 5. Quantitative phase analysis results (wt\%) for $s s-C_{4} A_{3} \bar{S}_{-} 1.16$ paste, as a function of hydration time obtained by SXRPD and LXRPD. $\mathrm{R}_{\mathrm{WP}}(\%)$ and $\chi^{2}$ Rietveld agreement factors are also given.

\begin{tabular}{|c|c|c|c|c|c|c|c|c|c|}
\hline \multicolumn{8}{|c|}{ SXRPD } & \multicolumn{2}{|c|}{ LXRPD } \\
\hline & $t_{0}$ & $6 h$ & $8 \mathrm{~h}$ & $12 \mathrm{~h}$ & 15h & $18 \mathrm{~h}$ & $24 h$ & $2 d$ & $7 d$ \\
\hline$s s-C_{4} A_{3} \bar{S}$ & $38.2(1)$ & $37.6(1)$ & $37.2(1)$ & $10.6(2)$ & $5.4(2)$ & $2.8(3)$ & $1.7(2)$ & $0.7(1)$ & 0 \\
\hline AFt & - & $0.5(2)$ & $0.9(2)$ & $5.4(2)$ & $6.3(3)$ & $6.7(3)$ & $7.0(3)$ & $14.7(1)$ & $12.7(1)$ \\
\hline AFm & - & - & - & $13.4(2)$ & $16.3(2)$ & $18.7(2)$ & $18.5(2)$ & $13.4(1)$ & 14.3(1) \\
\hline $\begin{array}{l}\text { ACn } \\
+ \text { FW }\end{array}$ & $\begin{array}{c}8.1(2) \\
+53.7^{*}=61.8\end{array}$ & $61.9(2)$ & $61.9(2)$ & $70.6(2)$ & $71.9(2)$ & $71.8(2)$ & $72.8(2)$ & $\begin{array}{c}58.0(5) \\
+13.1=71.1\end{array}$ & $\begin{array}{c}61.0(5) \\
+12=73.0\end{array}$ \\
\hline $\begin{array}{l}\mathrm{R}_{\mathrm{WP}} \\
(\%)\end{array}$ & 9.8 & 8.6 & 8.6 & 7.8 & 8.9 & 9.5 & 10.4 & 6.6 & 7.0 \\
\hline$\chi^{2}$ & 60.3 & 64.1 & 55.6 & 79.3 & 86.1 & 84.1 & 142.9 & 4.4 & 4.4 \\
\hline
\end{tabular}


Table 6. Quantitative phase analysis results (wt\%) for st- $C_{4} A_{3} \bar{S} \_$a_1.62 paste, as a function of hydration time obtained by SXRPD. $\mathrm{R}_{\mathrm{WP}}(\%)$ and $\chi^{2}$ Rietveld agreement factors are also given.

\begin{tabular}{c|ccccc}
\hline $\mathbf{W t} \%$ & $\mathbf{t}_{\mathbf{0}}$ & $\mathbf{1 h}$ & $\mathbf{2 h}$ & $\mathbf{3 h}$ & $\mathbf{7 h}$ \\
\hline $\mathbf{s t}-\boldsymbol{C}_{\mathbf{4}} \boldsymbol{A}_{\mathbf{3}} \overline{\boldsymbol{S}}$ & $23.9(1)$ & $25.0(1)$ & $17.2(1)$ & $2.3(2)$ & $0.7(1)$ \\
$\mathbf{C} \mathbf{\overline { S }}$ & $10.8(2)$ & $11.1(1)$ & $10.0(1)$ & $6.0(1)$ & $0.3(1)$ \\
$\mathbf{A F t}$ & - & $1.3(1)$ & $4.3(1)$ & $19.0(2)$ & $45.2(3)$ \\
$\mathbf{A F m}$ & - & - & $4.4(1)$ & $10.5(2)$ & $1.4(1)$ \\
$\mathbf{A C n}$ & $4.0(1)$ & $62.6(1)$ & $64.2(1)$ & $62.3(1)$ & $52.3(1)$ \\
$+\mathbf{F W}$ & $+61.3^{*}=65.3$ & & & & \\
$\mathrm{R}_{\mathrm{WP}}$ & & & & & \\
$(\mathbf{\%})$ & 5.5 & 3.2 & 3.8 & 6.2 & 3.9 \\
$\chi^{2}$ & 22.2 & 7.8 & 12.0 & 32.0 & 17.5 \\
\hline
\end{tabular}

*Theoretical free water content

Table 7. Quantitative phase analysis results (wt \%) for $s s-C_{4} A_{3} \bar{S} \_$a_1.62 paste, as a function of hydration time obtained by SXRPD. $\mathrm{R}_{\mathrm{WP}}(\%)$ and $\chi^{2}$ Rietveld agreement factors are also given.

\begin{tabular}{c|ccccc}
\hline $\mathbf{W t} \%$ & $\mathbf{t}_{\mathbf{0}}$ & $\mathbf{2 h}$ & $\mathbf{3 h}$ & $\mathbf{7 h}$ & $\mathbf{9 h}$ \\
\hline $\boldsymbol{s s}-\boldsymbol{C}_{\mathbf{4}} \boldsymbol{A}_{3} \overline{\boldsymbol{S}}$ & $20.6(1)$ & $22.4(1)$ & $22.6(1)$ & $20.4(1)$ & $17.8(1)$ \\
$\mathbf{C} \overline{\mathbf{S}}$ & $10.7(2)$ & $11.2(1)$ & $11.6(1)$ & $9.9(1)$ & $8.7(1)$ \\
$\mathbf{A F t}$ & - & - & $0.2(1)$ & $3.5(2)$ & $8.1(2)$ \\
$\mathbf{A C n}$ & $7.4(1)$ & $66.4(1)$ & $65.6(1)$ & $66.2(1)$ & $65.3(1)$ \\
$+\mathbf{F W}$ & $+61.3^{*}=68.7$ & & & & \\
$\mathrm{R}_{\mathrm{WP}}(\%)$ & 7.7 & 5.5 & 5.5 & 5.4 & 5.0 \\
$\chi^{2}$ & 63.5 & 29.8 & 28.5 & 21.7 & 16.6 \\
\hline
\end{tabular}

*Theoretical free water content 


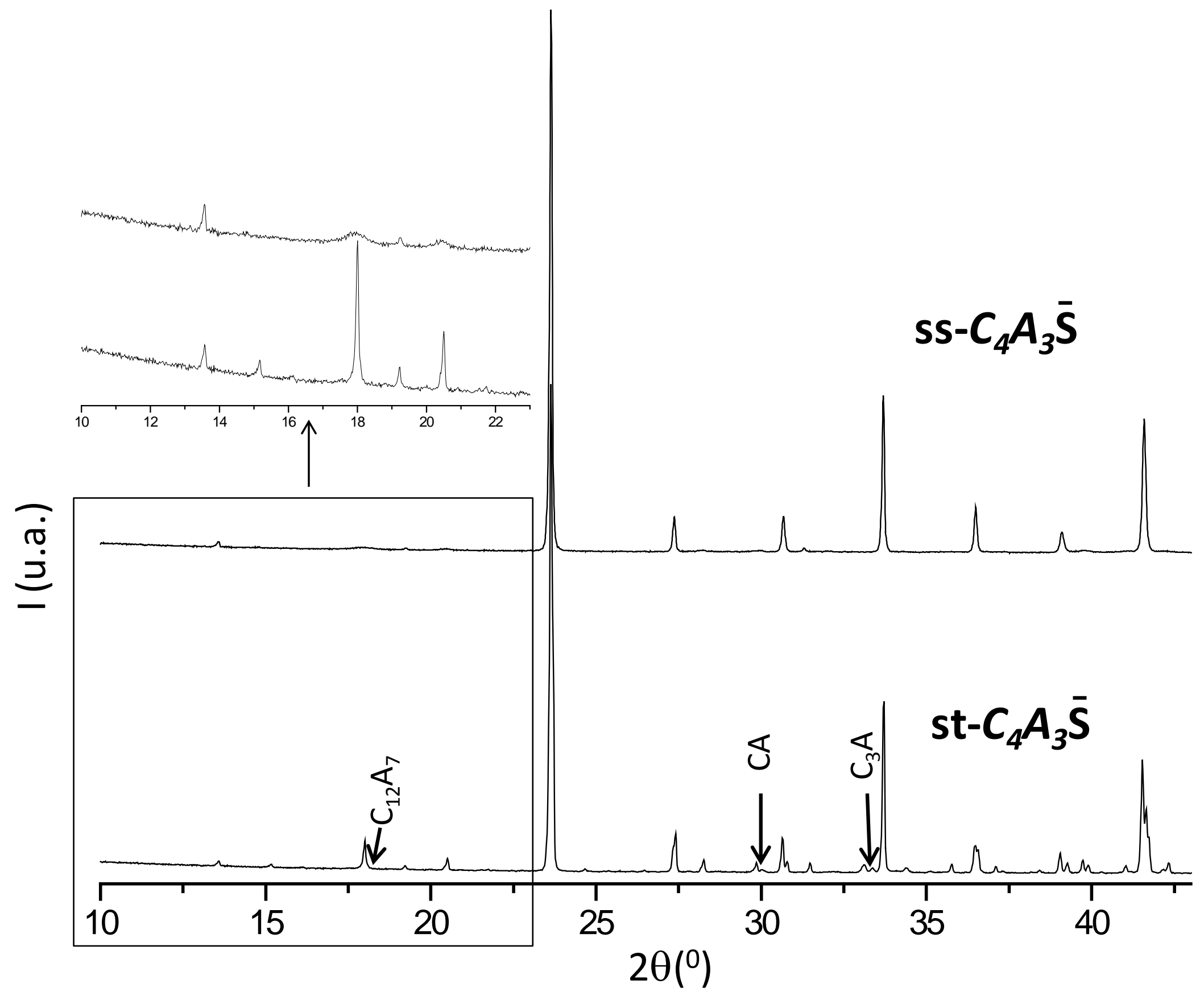

Figure 1 


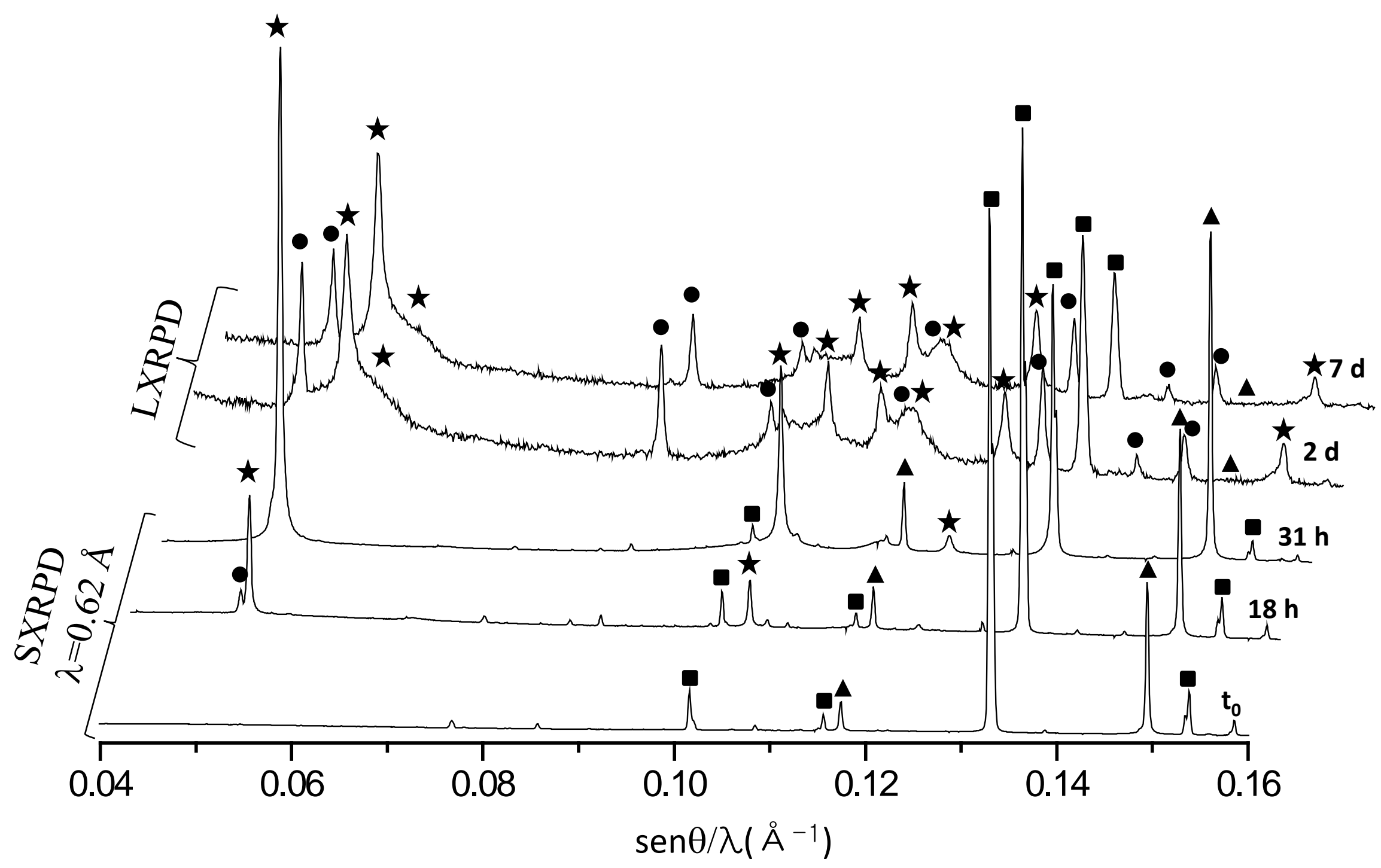

Figure 2 


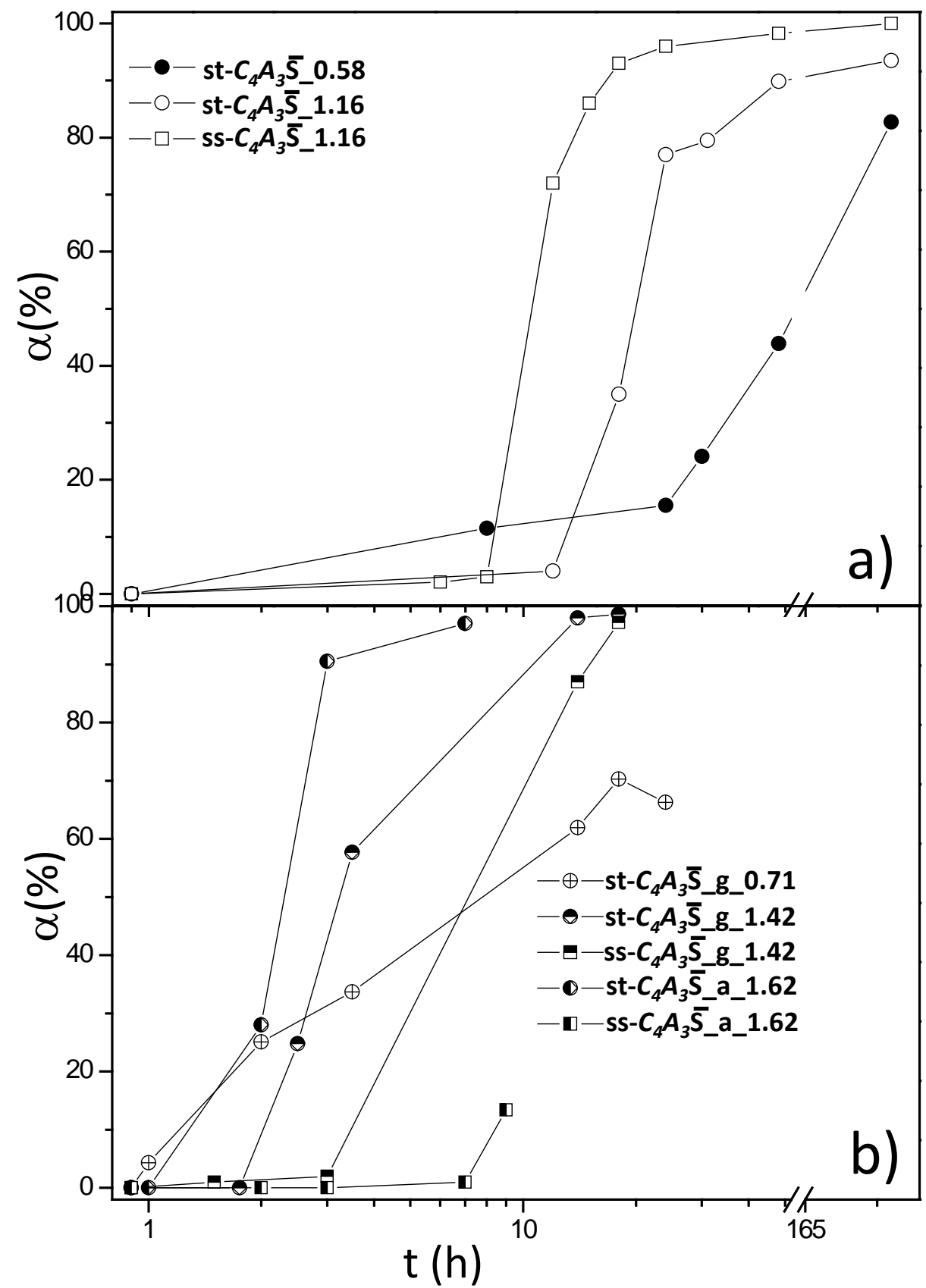

Figure 3 


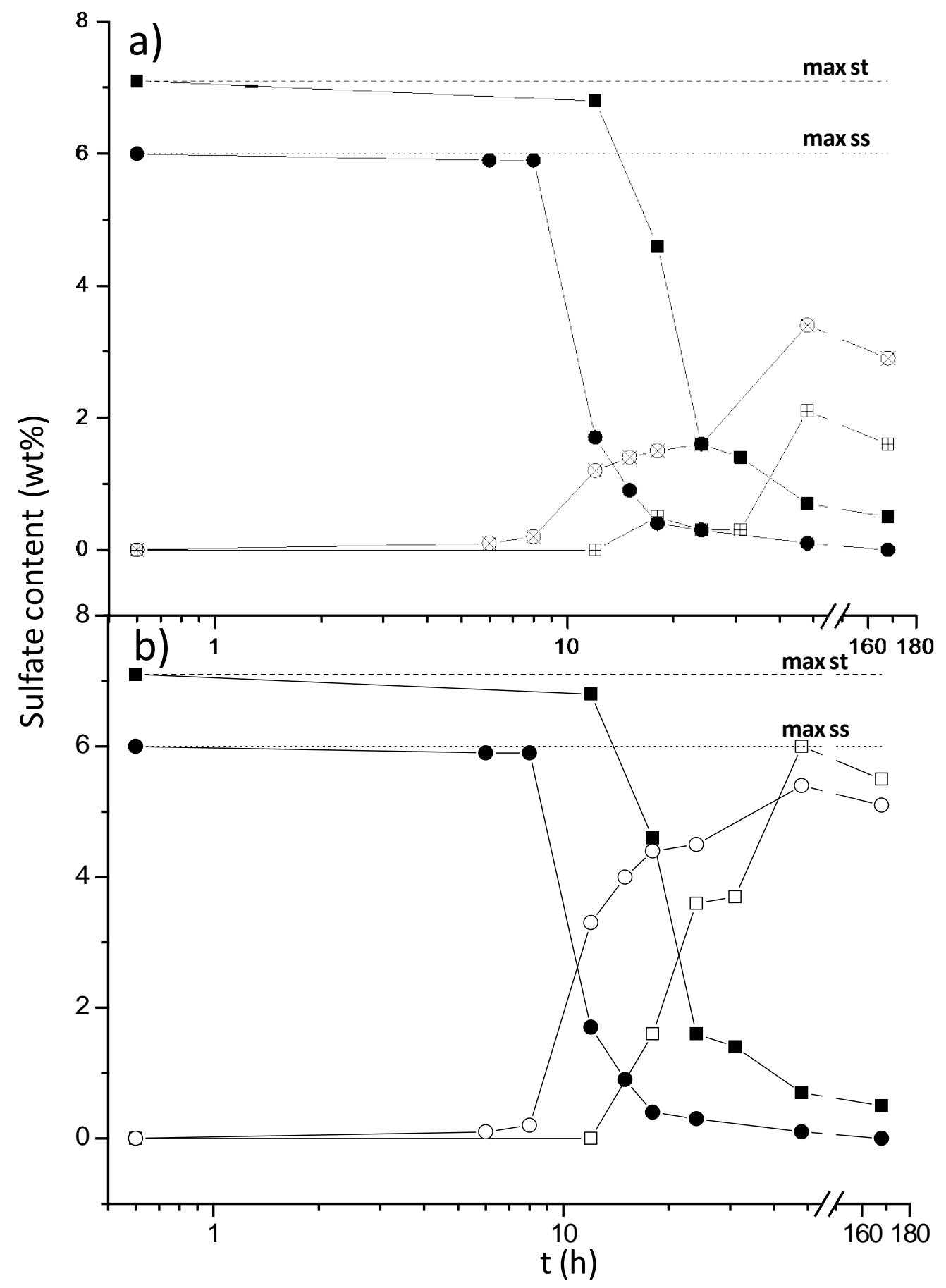

Figure 4 


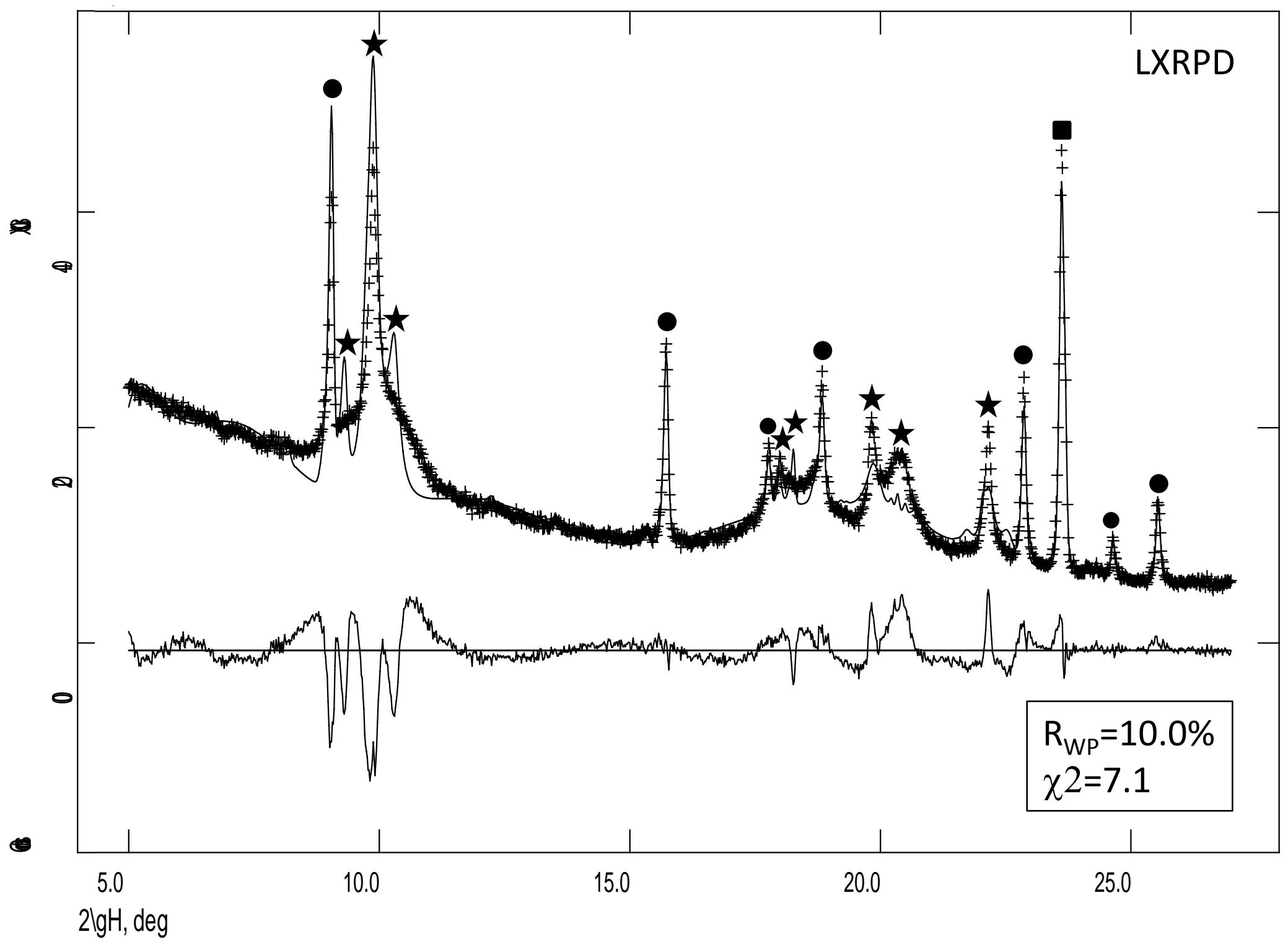

Figure 4

Figure 5 


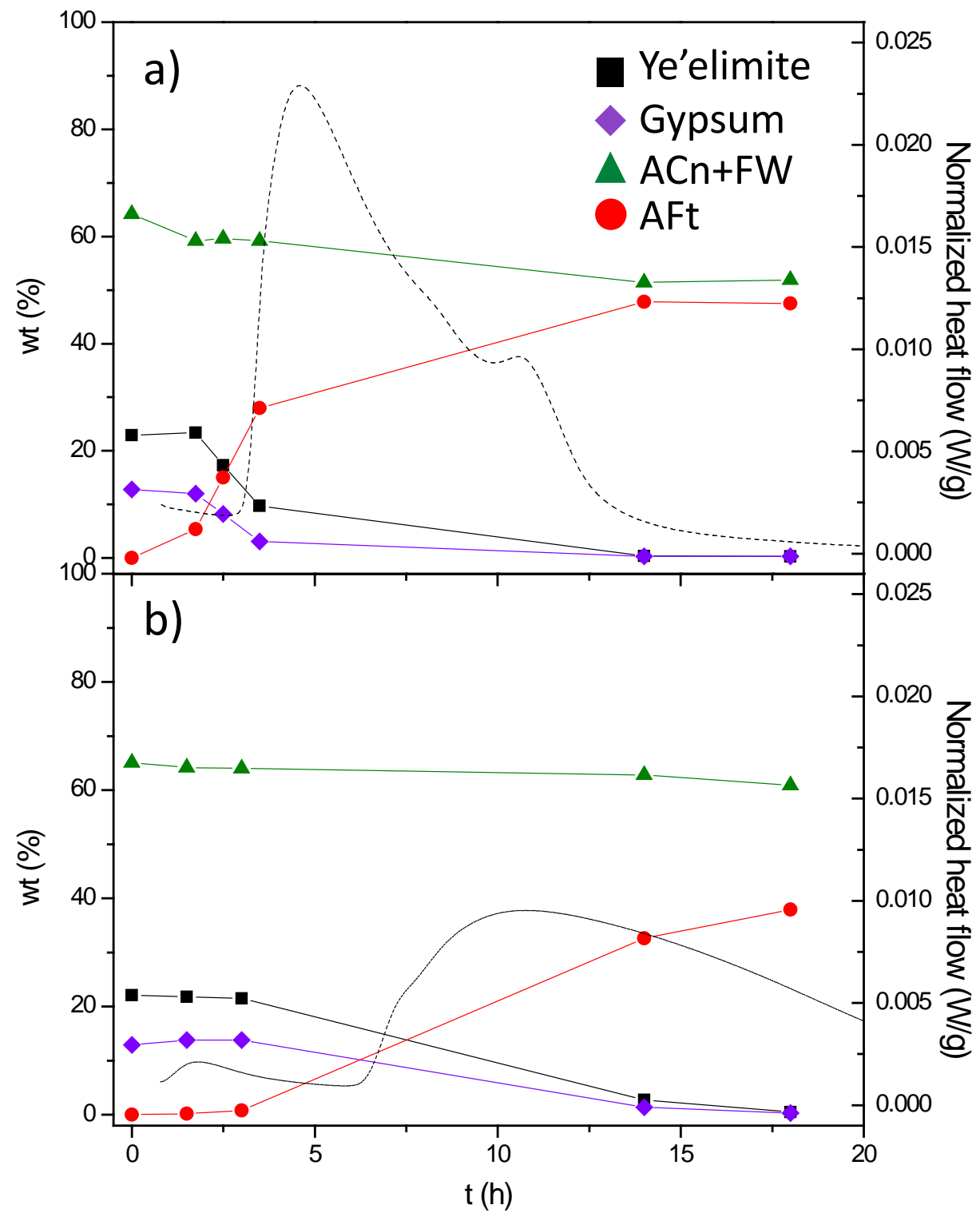

Figure 6 


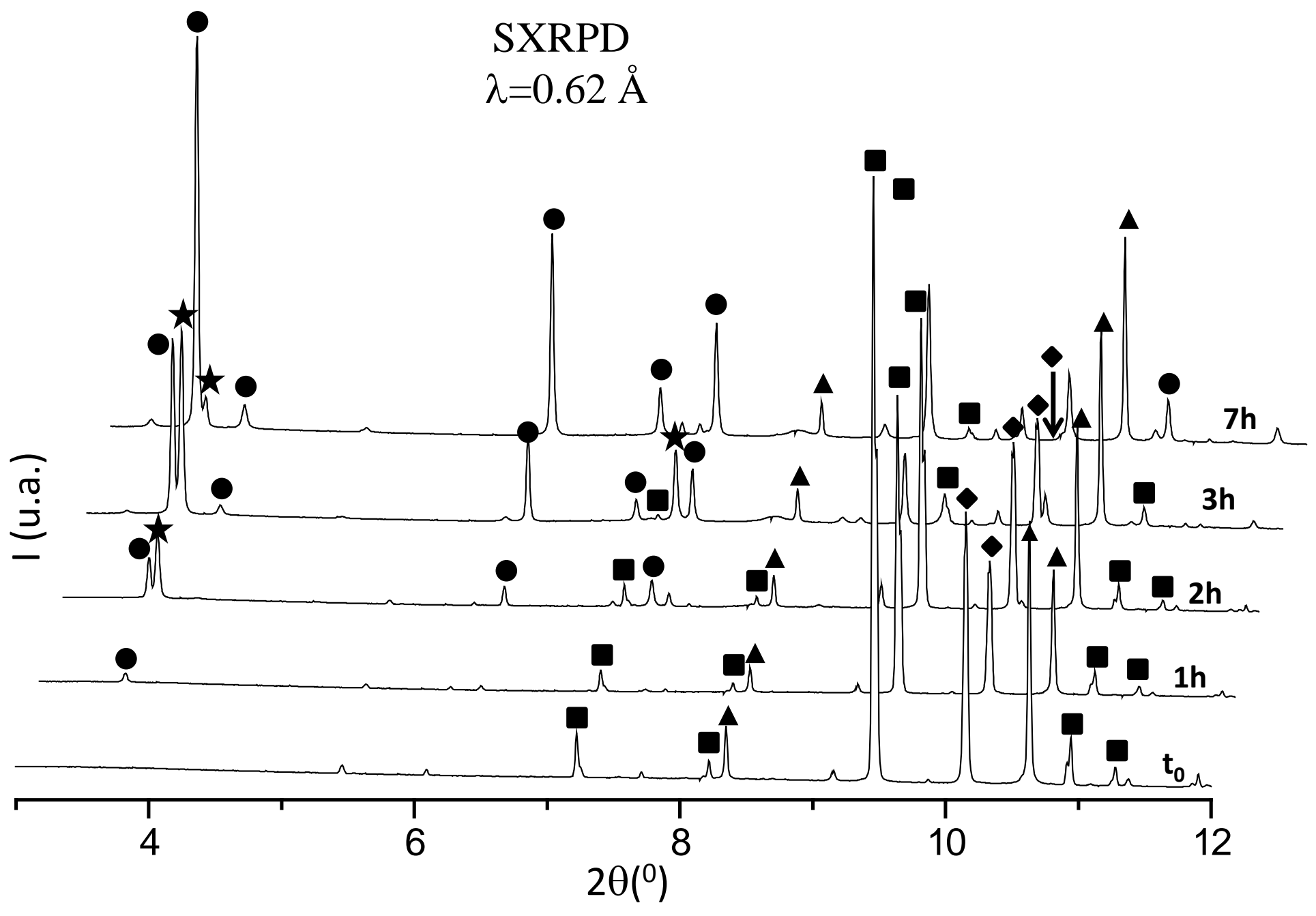

Figure 7 


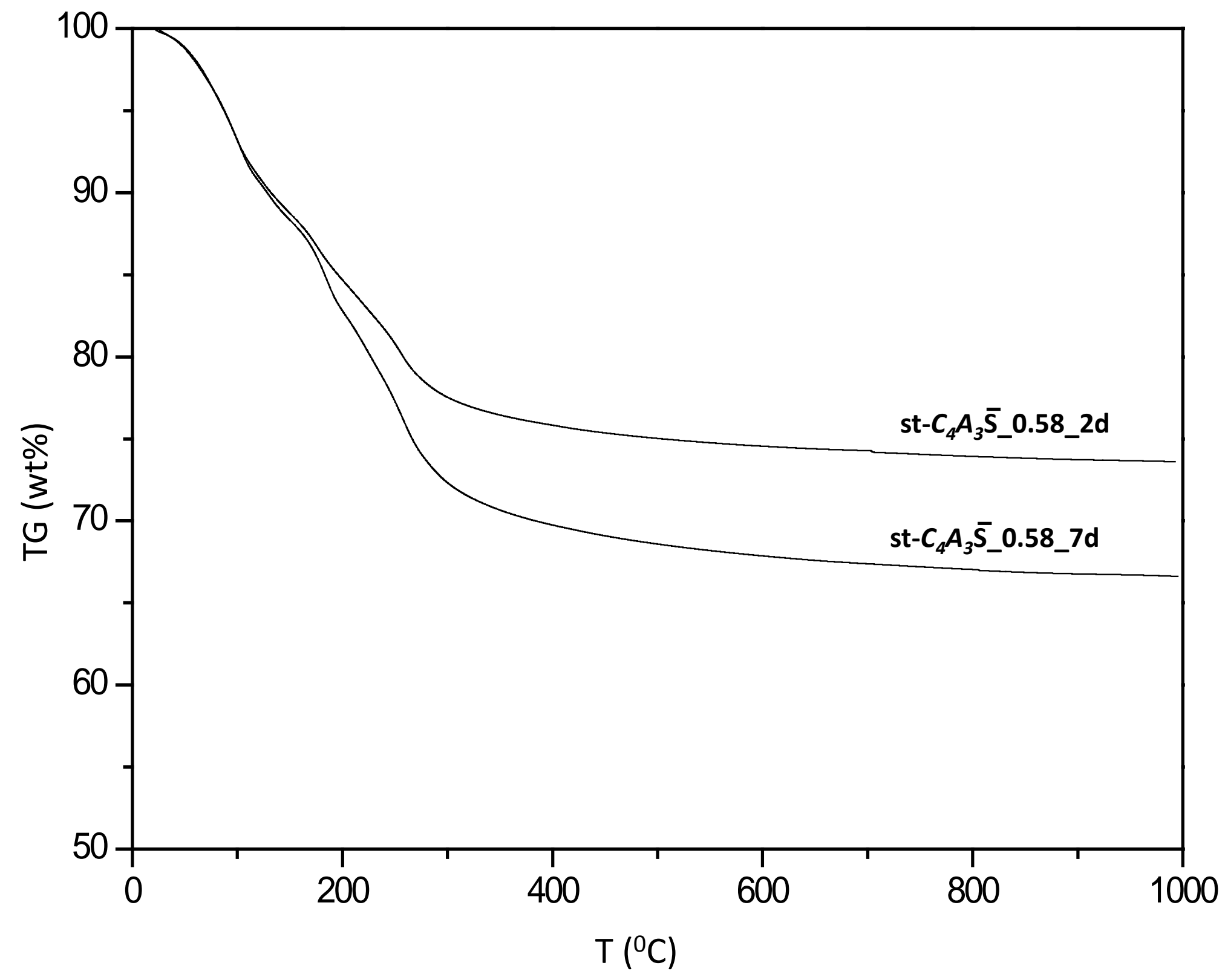

Figure S1 


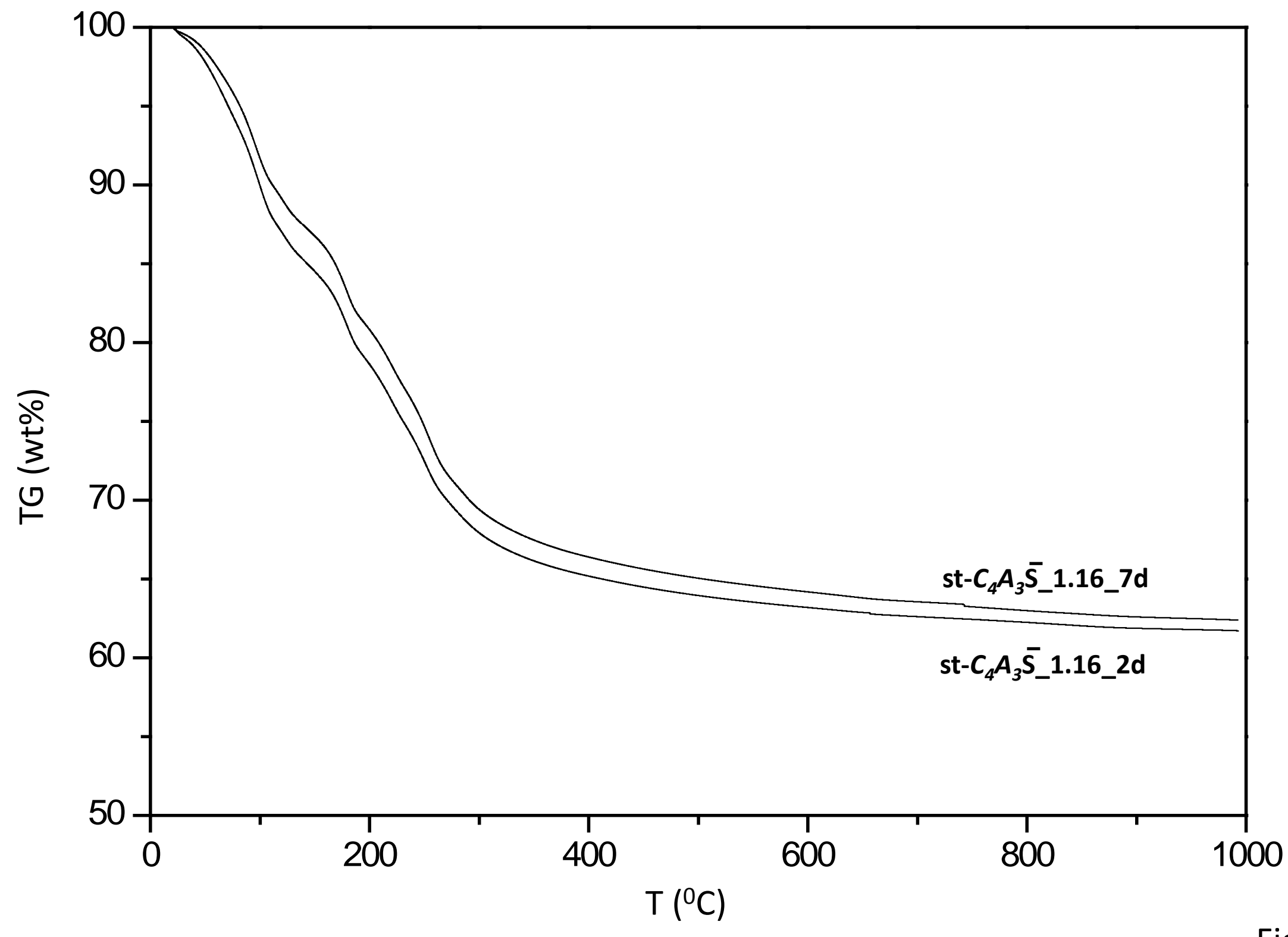

Figure S2 


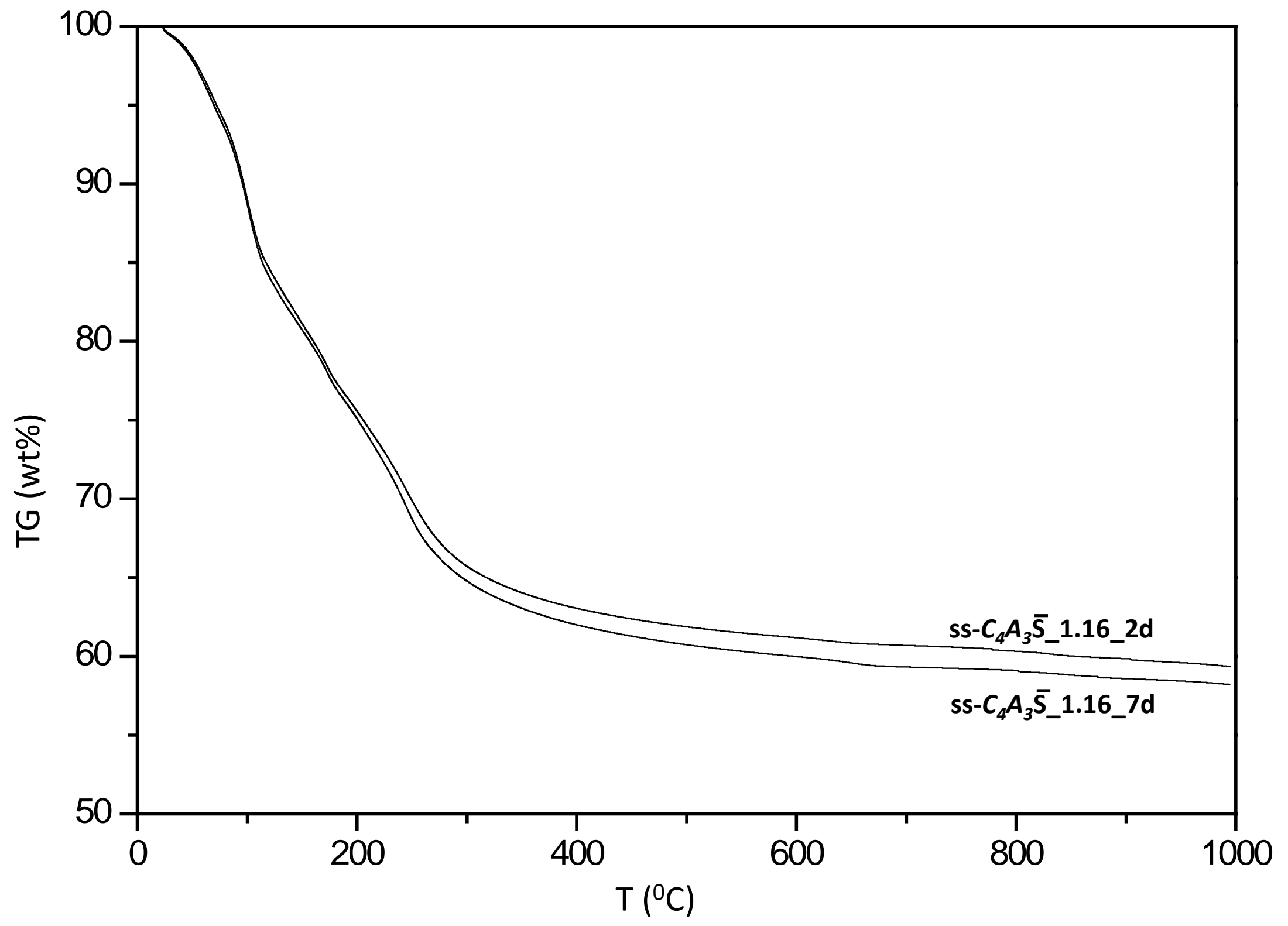

Figure S3 


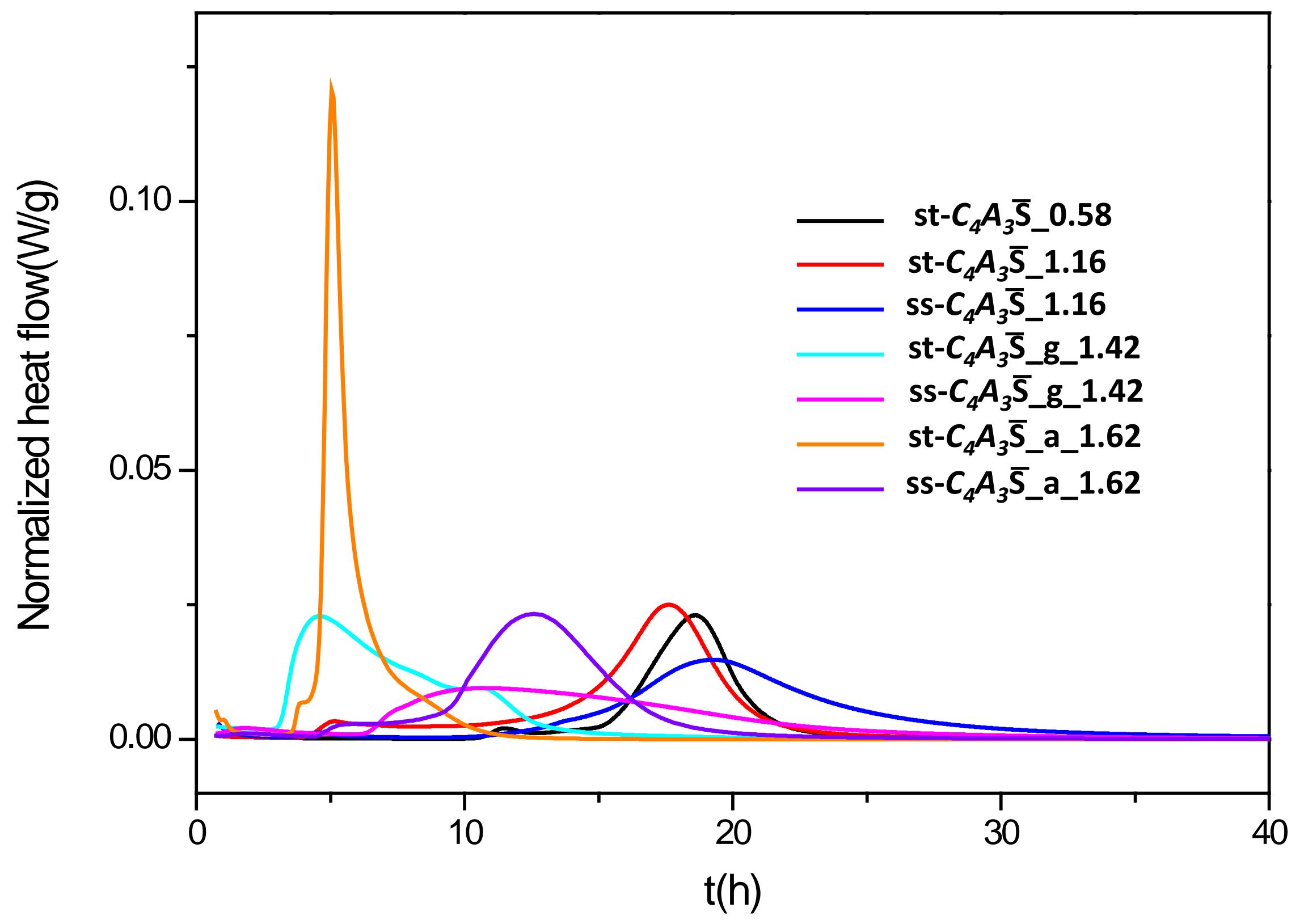

Figure S4 


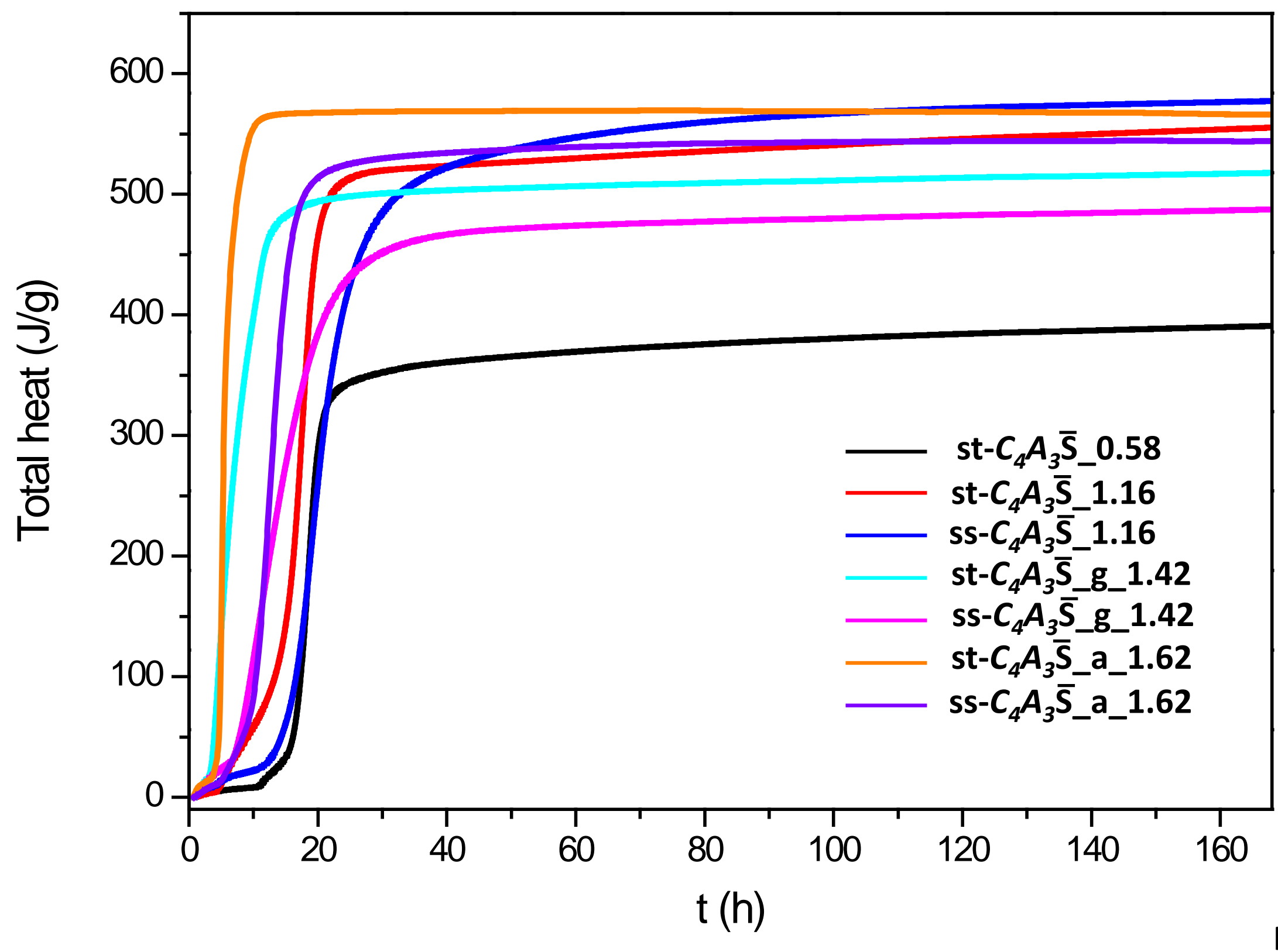

Figure S5 


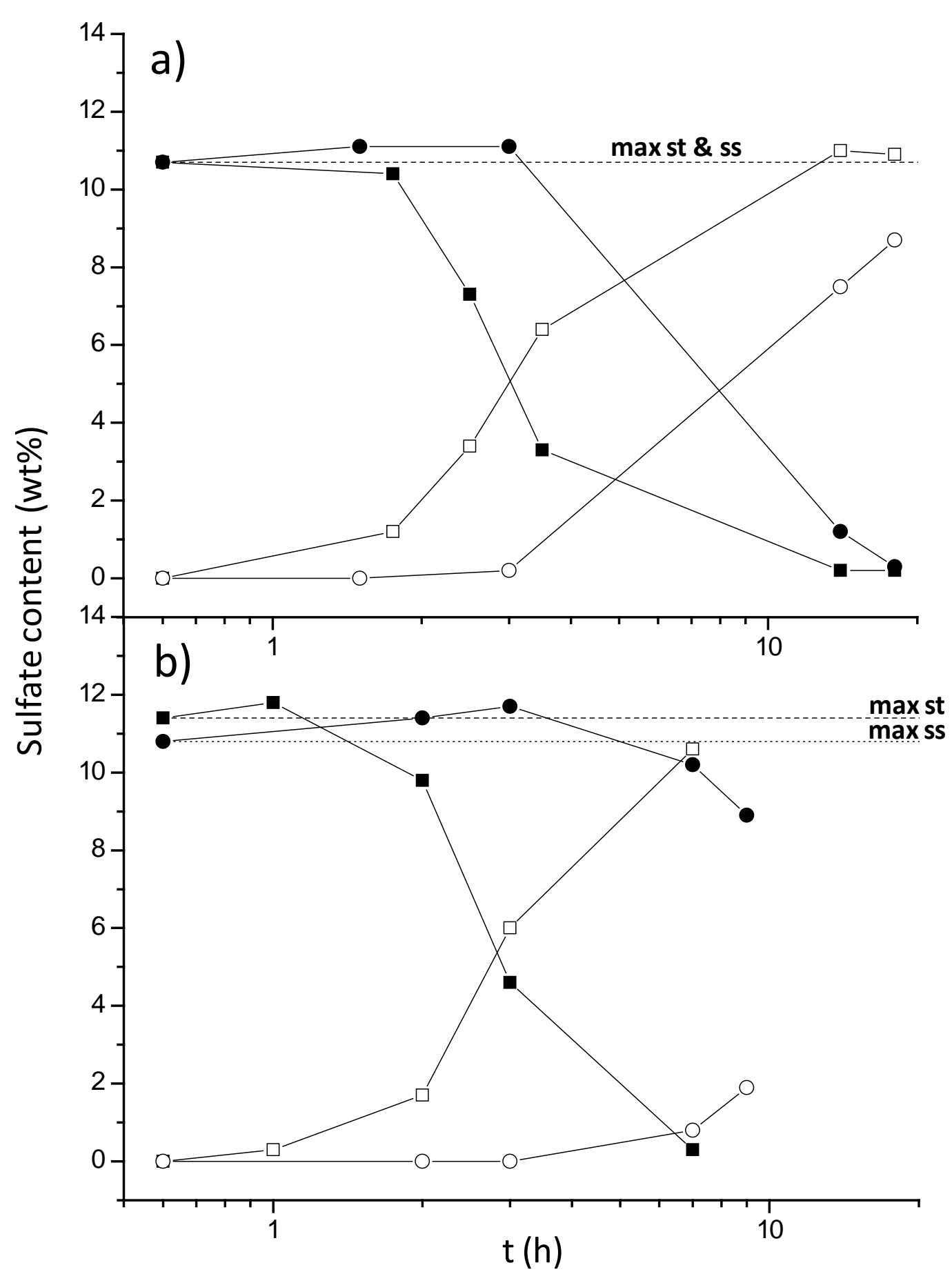

Figure S6 